\title{
Satellite Geomagnetism
}

\author{
Olsen, Nils; Stolle, Claudia
}

Published in:

Annual Review of Earth and Planetary Sciences

Link to article, DOI:

10.1146/annurev-earth-042711-105540

Publication date:

2012

Document Version

Publisher's PDF, also known as Version of record

Link back to DTU Orbit

Citation (APA):

Olsen, N., \& Stolle, C. (2012). Satellite Geomagnetism. Annual Review of Earth and Planetary Sciences, 40, 441-465. https://doi.org/10.1146/annurev-earth-042711-105540

\section{General rights}

Copyright and moral rights for the publications made accessible in the public portal are retained by the authors and/or other copyright owners and it is a condition of accessing publications that users recognise and abide by the legal requirements associated with these rights.

- Users may download and print one copy of any publication from the public portal for the purpose of private study or research.

- You may not further distribute the material or use it for any profit-making activity or commercial gain

- You may freely distribute the URL identifying the publication in the public portal

If you believe that this document breaches copyright please contact us providing details, and we will remove access to the work immediately and investigate your claim. 
Click here for quick links to

Annual Reviews content online, including:

- Other articles in this volume

- Top cited articles

- Top downloaded articles

- Our comprehensive search

\section{Satellite Geomagnetism}

\section{Nils Olsen and Claudia Stolle}

DTU Space, Technical University of Denmark, DK-2100 Copenhagen $\varnothing$, Denmark; email: nio@space.dtu.dk, cst@space.dtu.dk

\section{Keywords}

Earth's magnetic field, geomagnetic field modeling, magnetospheric and ionospheric currents

\begin{abstract}
Observations of Earth's magnetic field from space began more than 50 years ago. A continuous monitoring of the field using low Earth orbit (LEO) satellites, however, started only in 1999, and three satellites have taken highprecision measurements of the geomagnetic field during the past decade. The unprecedented time-space coverage of their data opened revolutionary new possibilities for monitoring, understanding, and exploring Earth's magnetic field. In the near future, the three-satellite constellation Swarm will ensure continuity of such measurement and provide enhanced possibilities to improve our ability to characterize and understand the many sources that contribute to Earth's magnetic field. In this review, we summarize investigations of Earth's interior and environment that have been possible through the analysis of high-precision magnetic field observations taken by LEO satellites.
\end{abstract}


LEO: low Earth orbit

CHAMP:

Challenging

Mini-Satellite Payload

(satellite)

\section{INTRODUCTION}

Geomagnetism concerns the exploration of Earth's interior and environment using observations of the magnetic field. Direct measurements of the field have been made for a few hundred years, and currently the field is monitored at approximately 150 geomagnetic observatories on ground. Their spatial distribution (see Figure 1) is, however, rather uneven, with large gaps in the oceans. Although considerable efforts have been made recently to fill some of these gaps by installing observatories at remote islands, a true global survey of the geomagnetic field is possible only with satellites.

A satellite in a low Earth orbit (LEO) moves at approximately $8 \mathrm{~km} \mathrm{~s}^{-1}$. As a consequence, it is not possible to decide whether an observed magnetic field variation is due to a temporal or spatial change of the field. This situation is rather different from that provided by magnetic measurements taken by observatories at fixed locations on the ground, for which an observed variation can always be attributed to a true temporal change of the field.

In general, satellites move around Earth in elliptical orbits, although orbit ellipticity is often small for satellites used in geomagnetism. Orbit inclination $i$ is the angle between the orbit plane and the equatorial plane, with $i=90^{\circ}$ representing a perfect polar orbit. Most satellite orbits have inclinations that are different from $90^{\circ}$. As an example, Figure 1 shows the ground track of one day (August 16, 2010) of the Challenging Mini-Satellite Payload (CHAMP) satellite, which has an orbit inclination of $i=87^{\circ}$. The polar gaps, the regions of half-angle $\left|90^{\circ}-i\right|$ around the geographic poles that are left unsampled, are obvious when the orbits are looked at in a polar view. The magnetic poles are, however, usually covered by satellite data because their distance from the geographic pole is larger than the size of the polar gap.

It is obvious that the spatial coverage even of one single day of satellite observations is better than that of the present ground observatory network. Satellite data spanning several months or even years therefore provide global data coverage that is far superior to what is possible close to Earth's surface (apart from the polar gap, of course).

However, there are some peculiarities of satellite data coverage, such as the occurrence of resonance patterns, when the satellite revisits a certain longitude every day and thus does not provide dense longitudinal coverage. In addition, the determination of reliable models of external field contributions requires good distribution not only regarding latitude and longitude but also in local time. These and related issues are discussed in more detail by Olsen et al. (2010).

For ground measurements of the magnetic field at a specific site, it is common to distinguish observatories, where the magnetic field is measured absolutely, and variometers, where only the field variation is measured, which means that the absolute level (the baseline) of the magnetic field is not known (and may even vary with time). Variometer data are therefore mainly used for studying temporal variations of the external field at periods (between seconds and days) shorter than that of the variability of the (unknown) baseline.

Also, for satellites, it is useful to distinguish between missions that measure the magnetic field absolutely (i.e., with a known baseline) and those that observe field variations only. The vast majority of magnetic satellites belong to the second category. Their data have been used successfully for studying ionospheric and magnetospheric processes, especially during geomagnetically disturbed conditions when the signal of those sources is particularly strong. However, many interesting external phenomena have amplitudes of only a few nanotesla (nT); still, they provide crucial information on ionospheric processes. Their reliable detection requires high-precision measurements of both magnetic field intensity and direction.

In this review, we concentrate on high-precision satellite missions, i.e., satellites that are capable of measuring the magnetic field absolutely and with high resolution. We discuss the science that is possible with data from those satellites and present highlights of the obtained results. 

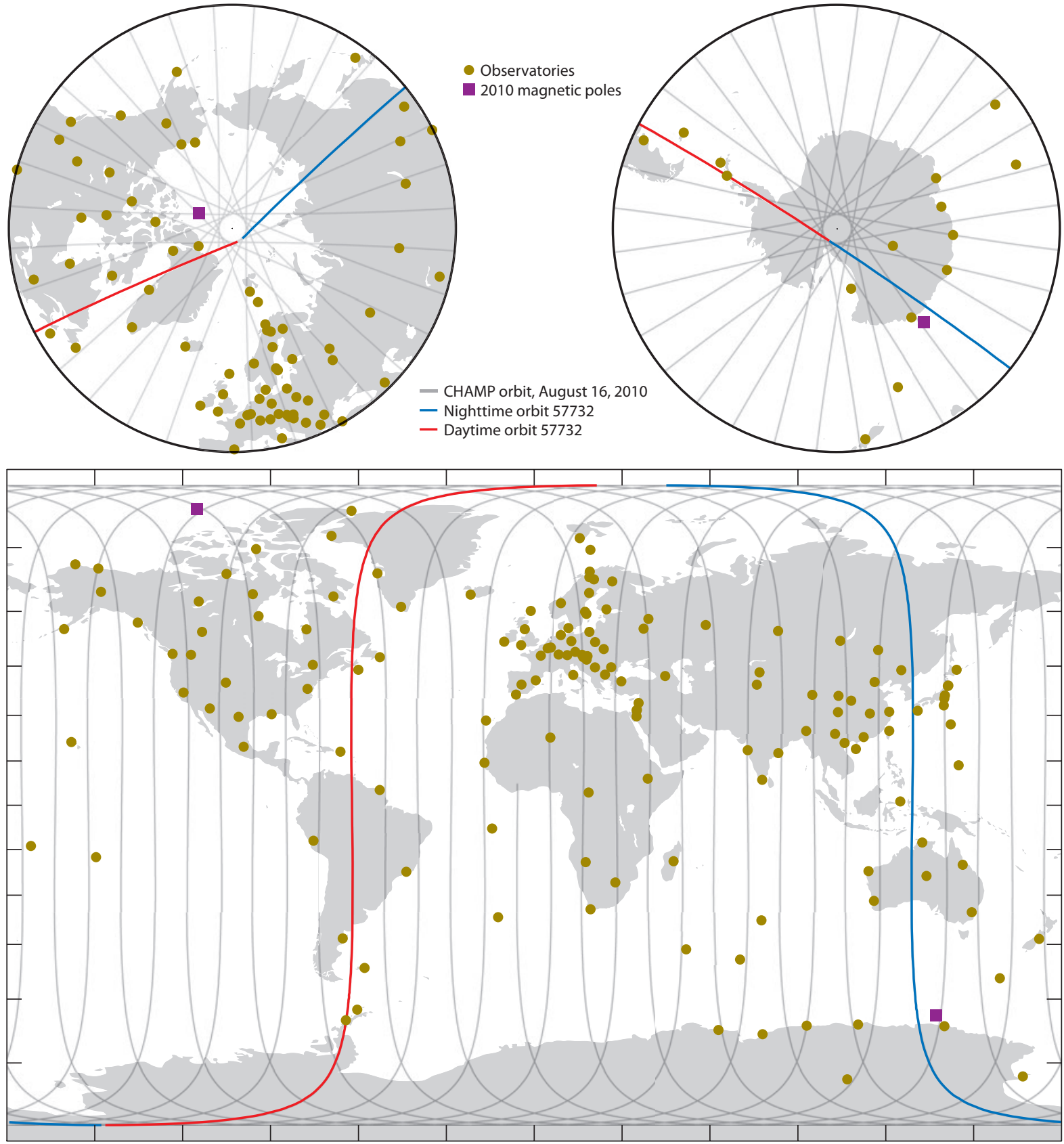

Figure 1

Ground track of $24 \mathrm{~h}$ of the CHAMP satellite orbit on August 16, 2010 (multiple gray curves). Highlighted is one particular orbit (orbit number 57732), when the satellite starts close to the geographic North pole and flies southward during local nighttime conditions (blue curve). After approximately $45 \mathrm{~min}$, it reaches its closest approach to the geographic South pole and moves northward on the dayside (red curve). Dark yellow dots indicate the locations of ground-based magnetic observatories. Locations of the magnetic poles in 2010 are shown by the purple squares. 
Table 1 Key parameters of high-precision magnetic satellites

\begin{tabular}{l|l|l|l|l}
\hline Satellite & \multicolumn{1}{|c|}{ Operation } & \multicolumn{1}{c|}{ Inclination } & \multicolumn{1}{c}{ Altitude } & \multicolumn{1}{c}{ Data } \\
\hline OGO-2 & Oct. 1965-Sept. 1967 & $87^{\circ}$ & $410-1,510 \mathrm{~km}$ & Scalar only \\
\hline OGO-4 & July 1967-Jan. 1969 & $86^{\circ}$ & $410-910 \mathrm{~km}$ & Scalar only \\
\hline OGO-6 & June 1969-June 1971 & $82^{\circ}$ & $400-1,100 \mathrm{~km}$ & Scalar only \\
\hline Magsat & Nov. 1979-May 1980 & $97^{\circ}$ & $325-550 \mathrm{~km}$ & Scalar and vector \\
\hline Orsted & Feb. 1999- & $97^{\circ}$ & $650-850 \mathrm{~km}$ & Scalar and vector \\
\hline CHAMP & July 2000-Sept. 2010 & $87^{\circ}$ & $260-450 \mathrm{~km}$ & Scalar and vector \\
\hline SAC-C & Jan. 2001-Dec. 2004 & $97^{\circ}$ & $698-705 \mathrm{~km}$ & Scalar only \\
\hline Swarm & $2012-$ & $88^{\circ} / 87^{\circ}$ & $530 /<450 \mathrm{~km}$ & Scalar and vector \\
\hline
\end{tabular}

Abbreviations: CHAMP, Challenging Mini-Satellite Payload; OGO, Orbiting Geophysical Observatories; SAC-C, Satellite de Aplicaciones Cientifico-C.

\subsection{Satellites for High-Precision Measurements of Earth's Magnetic Field}

Although the first measurements of the geomagnetic field from space were taken by the satellite Sputnik 3 in 1958 (followed by the Cosmos 26 and Cosmos 49 satellites in 1964), global highprecision mapping of Earth's magnetic field was not possible until the launch of the OGO-2 satellite in 1965. OGO-2 was part of the Polar Orbiting Geophysical Observatories (POGO) satellite series that consisted of six satellites, three of which (OGO-2, -4 and -6; see Cain 2007) flew at sufficiently low altitude (between 400 and $1500 \mathrm{~km}$ ) to be suitable for mapping Earth's magnetic field. These satellites measured the intensity of the magnetic field but not its direction.

A unique global determination of Earth's magnetic field only from intensity data is, however, not possible (see Backus 1970); some vector data are required in order to perform a unique description. This necessity stimulated the Magsat satellite mission (Purucker 2007), the first global vector survey, which flew for six months between November 1979 and April 1980.

Magsat was followed by a couple of initiatives for follow-on missions, but it was not until 20 years later, with the launch of the Ørsted satellite (Olsen 2007) in February 1999, that more recent magnetic satellite observations became available. Ørsted initiated a new era of exploring the geomagnetic field from space and marked the beginning of an effort known as the International Decade of Geopotential Field Research. Two additional satellites, CHAMP (Maus 2007) and Satellite de Aplicaciones Cientifico-C (SAC-C), were launched a couple of months after Ørsted. All three satellites carry essentially the same instrumentation and provide a unique data set that revolutionized space geomagnetism. These three satellites together provide data for more than one decade: Data from SAC-C are available until 2004, whereas CHAMP had its atmospheric reentry in September 2010. Only the Ørsted satellite still provides data (as of December 2011),

POGO: Polar Orbiting Geophysical Observatories, consisting of six satellites (OGO-1 to OGO-6)

SAC-C: Satellite de Aplicaciones Cientifico-C (third satellite of the Argentinean space program) but only measurements of the magnetic field intensity (vector data stopped at the end of 2004). Key parameters of these and other high-precision magnetic satellites are listed in Table $\mathbf{1 .}$

Also, the near future of space geomagnetism is bright: The European Space Agency is preparing the three-satellite constellation mission Swarm for launch in 2012 (Friis-Christensen et al. 2006). Swarm consists of a pair of side-by-side flying satellites at low altitude (450-km initial altitude at an east-west distance of $160 \mathrm{~km}$ at the equator) and a third satellite in a higher orbit. The mission is expected to perform the best-ever survey of Earth's magnetic field and its time changes.

\subsection{The Various Contributions to Earth's Magnetic Field}

The strength of the magnetic induction $\mathbf{B}$, hereafter referred to as the magnetic field for simplicity, varies at Earth's surface between approximately 25,000 nT near the equator and approximately 
65,000 nT near the poles $\left(1 \mathrm{nT}=10^{-9} \mathrm{~T}\right.$, with $1 \mathrm{~T}=1$ tesla $\left.=1 \mathrm{~V} \mathrm{~s}^{-1} \mathrm{~m}^{-2}\right)$. By far, the largest part of the magnetic field ( $95 \%$ or more at Earth's surface) is due to dynamo action in the core; magnetized material in the crust accounts, on average, for only a few percent of the total field but can locally reach magnitudes of several hundreds or even thousands of nanotesla close to Earth's surface. At satellite altitude, the crustal field is much weaker ( $<30 \mathrm{nT}$ at $400-\mathrm{km}$ altitude). Core and crustal fields together are denoted as internal sources (as they are located below Earth's surface) and are discussed in more detail in Sections 2.2 and 2.3.

In addition to contributions from these internal sources, there are contributions from electric currents in the ionosphere (90- to 1,000-km altitude) and the magnetosphere (at distances larger than several Earth radii); these are termed external sources. They are very dynamic, ranging from less than one nanotesla during geomagnetically quiet conditions to several hundreds or even thousands of nanotesla during disturbed times, with especially large amplitudes at polar latitudes.

Understanding the processes behind external sources is important in accounting for their signature when modeling the internal sources, either by data selection or data correction. Field contributions that perhaps are unwanted for scientists working on the core and crustal fields may be unique observations for the science community studying the ionosphere and magnetosphere. Indeed, several ionospheric and thermospheric phenomena could be studied for the first time using the high-precision magnetic field observations of the recent satellites Ørsted and CHAMP, although their primary purpose is mapping the internal field. Forward modeling of magnetic effects by a physics-based model of the ionosphere and thermosphere is reviewed in Richmond (2002). We provide in Section 3 an overview on how the various external sources are studied with satellites.

The time-changing external field induces secondary currents in Earth's interior, which, in turn, produce a secondary, induced magnetic contribution that adds to the primary, external one. Analyzing satellite magnetic observations (which contain the sum of primary and secondary fields) allows for a determination of mantle conductivity from space, a topic that is briefly discussed in Section 2.4.

The magnetic field measured by a satellite or from the ground is a superposition of contributions from these various sources, each of which has a specific spatial and temporal characteristic. A sketch of the various sources is given in Figure 2. The proper separation of the various contributions, based on magnetic measurements, is a major challenge, which, for instance, can be achieved by means of a spherical harmonic expansion (e.g., geomagnetic field modeling; see Section 2.1). In addition, for specific spatial and temporal scales, it is also possible to extract a certain field contribution by means of filtering and data selection.

What are typical spatial scales of the various field contributions? Figure 3 shows the magnetic field strength of the (static) internal field in dependence on horizontal wavelength $\lambda_{n}$ and spherical harmonic degree $n$, for a typical satellite altitude of $350 \mathrm{~km}$. Spatial scales down to $\approx 3,000 \mathrm{~km}$ (corresponding to spherical harmonics of degree $n=1-13$ ) are dominated by contributions from the core field, whereas spatial scales smaller than $\approx 3,000 \mathrm{~km}$ (corresponding to $n \geq 14$ ) are dominated by contributions from the crustal field. Also shown are typical amplitude and spatial scales for some external sources. They partly overlap those of internal sources, and therefore high-quality geomagnetic field models of the core and crustal fields have to be removed from the observations before they can be used in external field studies.

However, note that the satellite movement hampers the process of separation between spatial and temporal changes of the field. The scale at the top of Figure 3 shows (for a satellite moving at $8 \mathrm{~km} \mathrm{~s}^{-1}$ ) the time period $\tau$ that would correspond to the presented spatial scales. For example, the magnetic signature of a pulsation of 150 -s period on a certain satellite track looks similar to that of a spatial structure (e.g., crustal field signature) of roughly 1,200-km scale. 


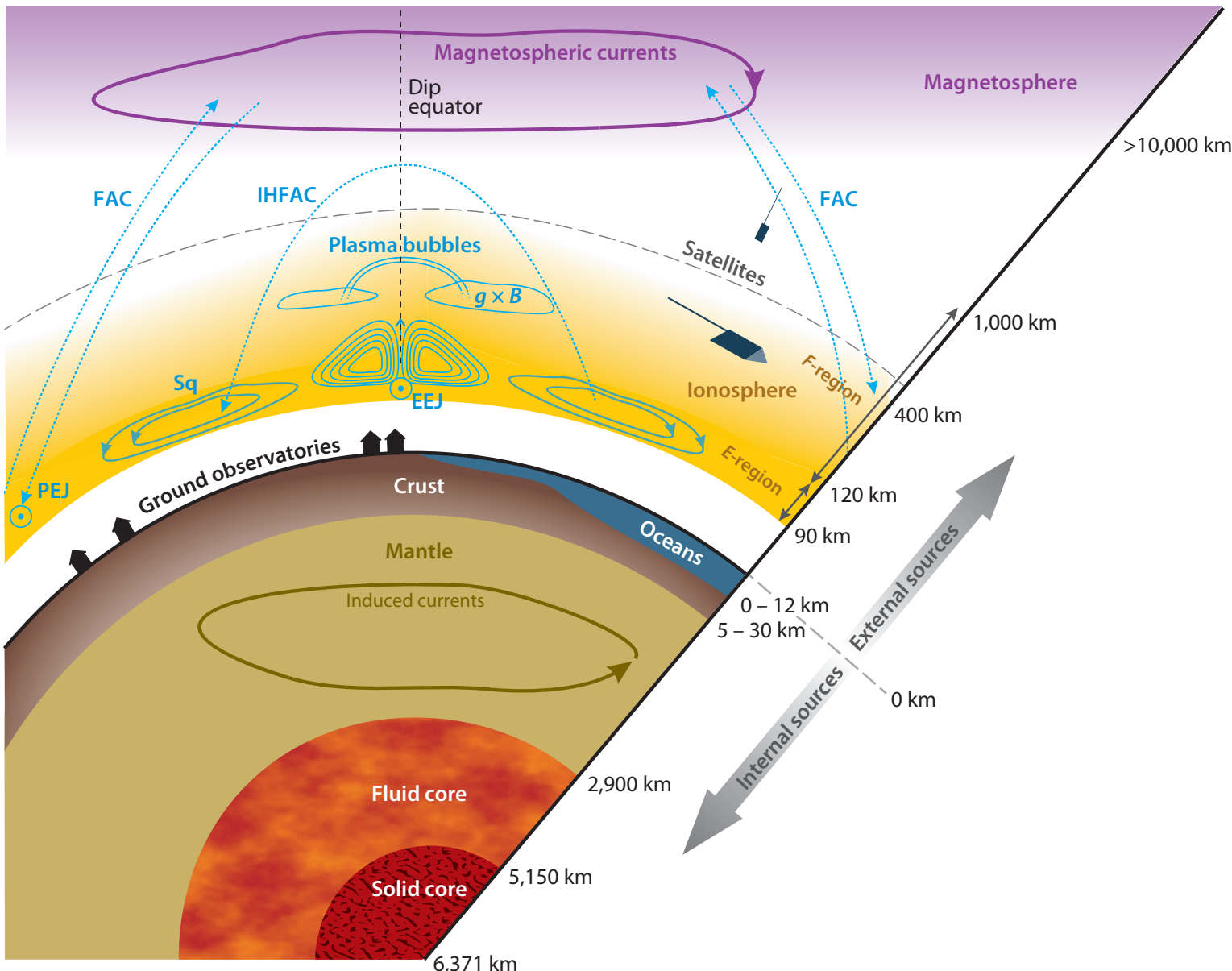

Figure 2

Sketch of the various sources contributing to the near-Earth magnetic field. Abbreviations: $B$, ambient magnetic field; EEJ, equatorial electrojet; FAC, field-aligned current; $g$, Earth's gravity vector; IHFAC, interhemispheric field-aligned current; PEJ, polar electrojet; $\mathrm{Sq}$, solar quiet daily magnetic variation.

Quasi-Dipole (QD): describes coordinates defined by the geometry of Earth's magnetic field

LT: local time
What do magnetic field observations along a typical satellite track look like? Figure $4 \boldsymbol{a}, \boldsymbol{b}$ shows the difference $\Delta F=F_{\text {obs }}-F_{\text {core }}$ between observed magnetic intensity $F_{\text {obs }}$ and the core field part (magnetic field contribution from Earth's core) $F_{\text {core }}$ as given by the geomagnetic field model CHAOS-4 (Olsen et al. 2011) for the nighttime part of CHAMP orbit number 57732, in dependence on Quasi-Dipole (QD) latitude (Richmond 1995). The ground track of that orbital part is shown in Figure 1; local time (LT) of the equator crossing was 23:35 LT. The core field part along that orbit varies between $\approx 34,000$ nT near the equator and $\approx 55,000$ nT near the poles, which is by far the largest contribution to the observed magnetic field and dominates contributions from other sources. Figure $4 a, b$ also shows the observed magnetic field minus the core magnetic field predicted by the CHAOS-4 model and the predicted crustal field as given by the model MF7 (Maus 2010a).

The difference between these two curves, i.e., the observed values minus model values for the core and the crust, is shown in Figure $4 c, d$. Because the internal sources (from the core and 


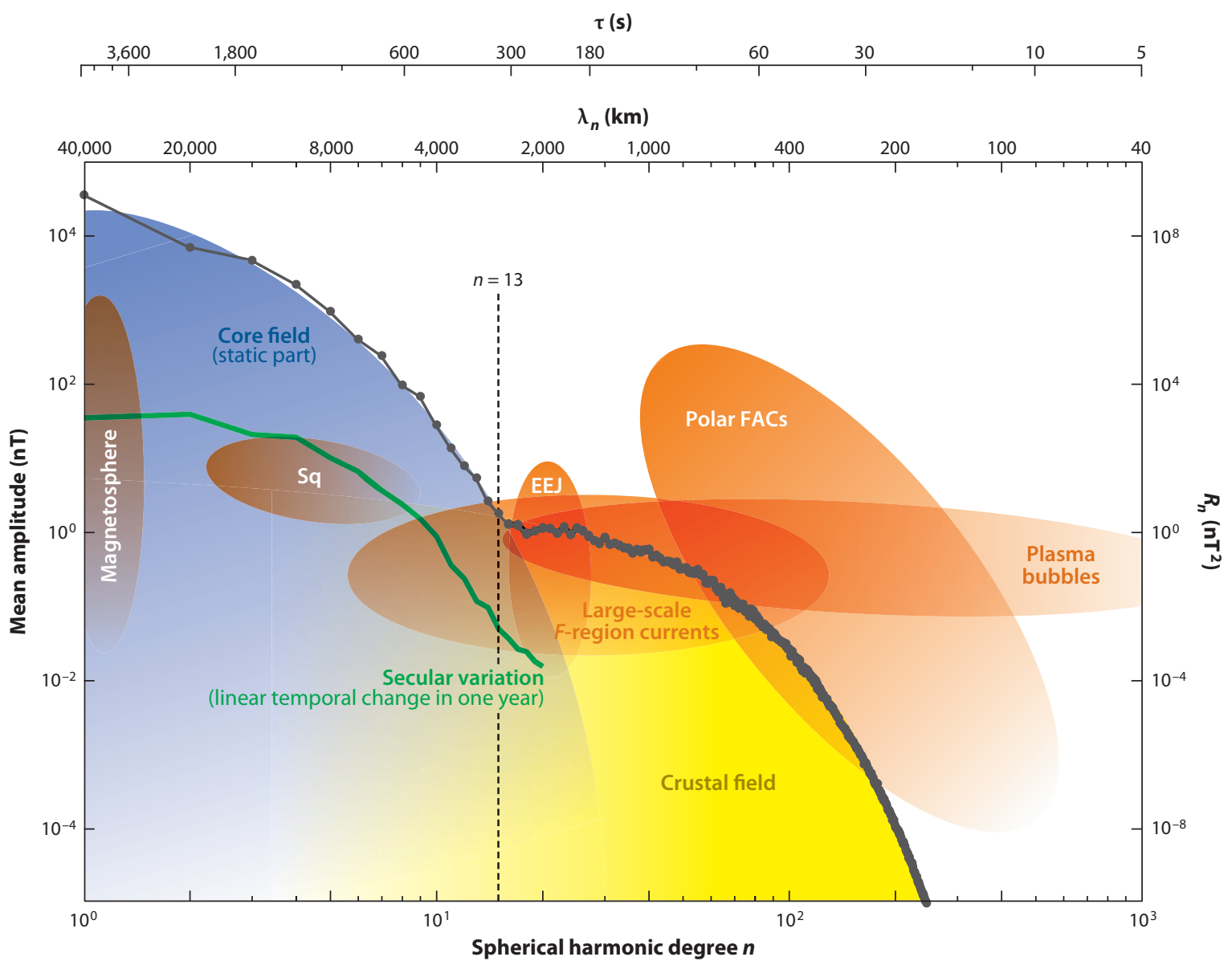

Figure 3

The magnetic field strength of the (static) internal field in dependence on horizontal wavelength $\lambda_{n}$ (top axis) and spherical harmonic degree $n$ (bottom axis), for a typical satellite altitude of $350 \mathrm{~km}$, as given by the field models CHAOS-4 (Olsen et al. 2011) for $n \leq 90$, MF7 (Maus 2010a) for $90<n \leq 133$, and NGDC-720 (Maus 2010b) for $n>133$. The gray curve is for the static field, whereas the green curve shows the linear time change (secular variation) in one year. Amplitudes and spatial scales for various external fields are indicated by the orange areas. The scale at the top shows, for a satellite moving at $8 \mathrm{~km} \mathrm{~s}^{-1}$, the time period $\tau$ that would correspond to the presented spatial scales. Abbreviations: EEJ, equatorial electrojet; FAC, field-aligned current; $\mathrm{nT}$, nanotesla; $R_{n}$, spatial power spectrum; Sq, solar quiet daily magnetic variation.

crust) have been removed, the remaining magnetic field signal is caused by external sources (plus their Earth-induced, electromagnetically induced counterparts). Although the selected orbit is from a geomagnetically quiet day (global activity index $K p$ on August 16, 2010: $1^{-} \leq K p \leq 2^{\circ}$ ), there is a significant external field contribution, the large-scale part of which is dominated by magnetospheric currents. Values for this part as given by CHAOS-4 are shown in Figure $4 \boldsymbol{c}, \boldsymbol{d}$, whereas Figure $4 e, f$ shows the magnetic field intensity after removal of that magnetospheric contribution. Remaining signals result from ionospheric sources. Because ionospheric conductivity is low during the night (owing to vanishing ionizing solar irradiation), only weak ionospheric contributions are expected. Indeed, at middle and low latitudes ( $\pm 60^{\circ}$ latitude), the magnetic field along the satellite track is almost undisturbed apart from a variation of a few nanotesla, which
Kp: 3 -h index monitoring global geomagnetic activity 

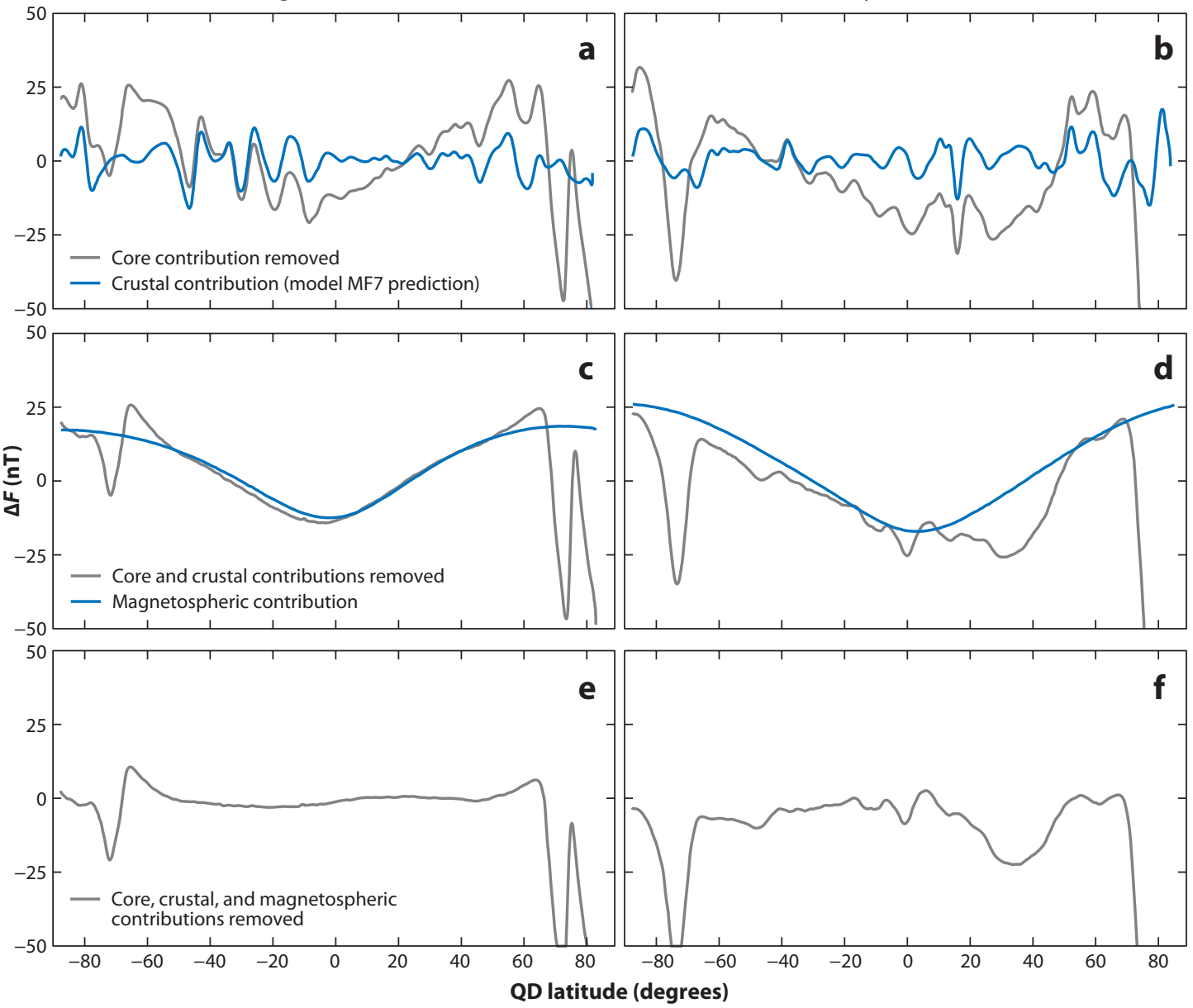

Figure 4

(a,c,e) Magnetic field intensity residuals versus Quasi-Dipole (QD) latitude for the nighttime part of CHAMP orbit number 57732 of August 16, 2010. $(b, d, f)$ Same as in panels $a, c$, and $e$, but for the daytime part of the orbit. $(a, b)$ The gray curve shows the difference between observed magnetic intensity $F_{\text {obs }}$ and the core field part (magnetic field contribution from Earth's core) $F_{\text {core }}\left(\Delta F=F_{\text {obs }}-\right.$ $\left.F_{\text {core }}\right)$. The blue curve shows the predicted crustal field as given by the model MF7 (Maus 2010a). $(c, d)$ The gray curve indicates the difference between the two curves shown in panels $a$ and $b$, i.e., the observed values minus the model values for the core and the crust. The blue curve indicates the modeled contributions of magnetospheric currents. $(e, f)$ The magnetic field intensity after removal of the contributions represented by the blue curves in panels $c$ and $d$. Abbreviations: LT, local time; nT, nanotesla; UT, universal time.

Field-aligned current (FAC): electric current flowing along the field lines of the ambient magnetic field might result from an imperfect removal of the magnetospheric signal. However, at high latitudes, there occur large fluctuations due to auroral current systems in the $E$-region and field-aligned currents (FACs) that connect to the magnetosphere. Their amplitudes are stronger in the sunlit (Northern) polar region than in the dark (Southern) polar region.

A similar plot, but for the dayside part of the orbit (equator crossing at 11:35 LT), is shown in Figure $4 b, d, f$. After removal of contributions from the core, crust, and magnetosphere, significant signals remain even at low and middle latitudes (Figure $4 f$ ). A large-scale field depression is 
visible at approximately $40^{\circ} \mathrm{N}$. This variation is due to mid-latitude $E$-region dynamo currents (see Section 3.2). At low latitudes, the equatorial electrojet (EEJ) is clearly visible as a reduction at the magnetic dip equator $\left(0^{\circ} \mathrm{QD}\right.$ latitude). At approximately $\pm 15^{\circ}$ latitude, the field depression is due to the diamagnetic effect of the two high-electron-density bands symmetrical about the dip equator, termed the Appleton anomaly.

The signature of these external sources is of similar strength and spatial scale as that of the crustal field, and removal of a good field model is therefore crucial to investigate the other, much weaker, field contributions. An examination of Figure $4 e, f$ clarifies why usually only data from dark regions, when ionospheric contributions are significantly reduced compared with sunlit regions, are taken for modeling the core and crustal field.

\section{CORE, CRUST, AND MANTLE}

\subsection{Geomagnetic Field Modeling}

The most common approach to describing the geomagnetic field globally, and to separating internal and external sources, is by means of a spherical harmonic expansion (see section 5.02.3 of Hulot et al. 2007 for alternative ways of representing the field). Following Backus (1986), the magnetic field $\mathbf{B}=\mathbf{B}_{\text {int }}+\mathbf{B}_{\text {ext }}+\mathbf{B}_{\text {tor }}$ on a sphere can be decomposed into potential fields $\mathbf{B}_{\text {int }}$ due to sources below and $\mathbf{B}_{\text {ext }}$ due to sources above that reference sphere, and a nonpotential (in this case, toroidal) field $\mathbf{B}_{\text {tor }}$ produced by electrical currents crossing the sphere.

The last vanishes in regions without electrical currents. In that case, the magnetic field consists only of the two potential fields $\mathbf{B}_{\text {int }}=-\nabla V_{\text {int }}$ and $\mathbf{B}_{\text {ext }}=-\nabla V_{\text {ext }}$. Each of the two potentials can be expanded into a series of spherical harmonics:

$$
\begin{aligned}
V_{\mathrm{int}} & =a \sum_{n=1}^{N_{\mathrm{int}}} \sum_{m=0}^{n}\left(g_{n}^{m} \cos m \phi+b_{n}^{m} \sin m \phi\right)\left(\frac{a}{r}\right)^{n+1} P_{n}^{m}(\cos \theta) \\
V_{\mathrm{ext}} & =a \sum_{n=1}^{N_{\mathrm{ext}}} \sum_{m=0}^{n}\left(q_{n}^{m} \cos m \phi+s_{n}^{m} \sin m \phi\right)\left(\frac{r}{a}\right)^{n} P_{n}^{m}(\cos \theta),
\end{aligned}
$$

where $a=6,371.2 \mathrm{~km}$ is the reference radius (mean Earth radius) traditionally used in geomagnetism, $(r, \theta, \phi)$ are spherical geographic coordinates, $P_{n}^{m}$ are the associated Schmidt seminormalized Legendre functions, $\left\{g_{n}^{m}, b_{n}^{m}\right\}$ are the Gauss coefficients describing internal sources, $\left\{q_{n}^{m}, s_{n}^{m}\right\}$ are the Gauss coefficients describing external sources, and $N_{\text {int }}\left(N_{\text {ext }}\right)$ is the maximum spherical harmonic degree and order of the internal (external) expansion. The Gauss coefficients may depend on time, for example, to account for core field changes or to describe the temporal variations of external contributions.

At satellite altitude, in situ electrical currents cause magnetic field contributions that cannot be described by the potential approach of Equation (1). Nevertheless, a potential description of the observed field is commonly used for analyzing satellite data, often after careful data selection to minimize external field contributions (e.g., by use of data from the nightside part of the orbits, to reduce the effect of ionospheric fields, as shown in Figure 4).

The mean-squared magnetic field intensity corresponding to internal magnetic field contributions of spatial scale $\lambda_{n}=2 \pi r /(n+1 / 2)$ and averaged over a sphere of radius $r$ is given as

$$
R_{n}=(n+1)\left(\frac{a}{r}\right)^{2 n+4} \sum_{m=0}^{n}\left[\left(g_{n}^{m}\right)^{2}+\left(b_{n}^{m}\right)^{2}\right] .
$$

Equatorial electrojet (EEJ): ionospheric E-region current flowing along the dayside magnetic equator 
In the following sections, we use the spatial power spectrum $R_{n}$ to assess models of the core and crustal fields.

\subsection{Core Field and Secular Variation}

The first global magnetic models based on magnetic field observations from space were derived by Tyurmina \& Cherevko (1967) using data from the Cosmos 49 satellite and by Cain et al. (1967) using data from the OGO-2 satellite. These were models of the static field only; the limited time span of the satellite data did not allow the resolution of temporal changes. A review of these and other early satellite models of the core field is provided by Langel (1987).

Here we concentrate on the achievements obtained during the past decade, during which field models of increasing complexity have been derived using data from the three satellites-Ørsted, CHAMP, and SAC-C - that have been continuously monitoring the geomagnetic field since 1999. See also Lesur et al. (2011) for a review of core field models derived from recent satellite data.

The first satellite-based models were snapshot models that described the field at a specific epoch (e.g., Hulot et al. 2002, Olsen et al. 2000). This approach is similar to the one used to derive models (e.g., Langel \& Estes 1985b) from data taken by the Magsat satellite, which flew only for a couple of months. The difference between two snapshot models describing the geomagnetic field at different epochs yields the mean time change (secular variation) over the considered time span; this approach has been used, for example, by Hulot et al. (2002) to study the behavior of the geomagnetic field between 1980 (Magsat) and 2000 (Ørsted), in particular regarding its hemispheric asymmetry, the growth of the region of weak field in the South Atlantic, and the overall decline of the dipole field.

The next step of modeling complexity concerns models for which the time dependence of the core field is parameterized by a Taylor expansion; examples for this class of models are given by Langlais et al. (2003), Maus et al. (2005a, 2006), Olsen (2002), and Thomson \& Lesur (2007). However, the temporal changes of the core field can no longer be regarded linear (or quadratic) if observations spanning more than, say, two or three years are analyzed (inclusion of higher-order terms may lead to unwanted behaviors near the edges of the time interval). This is demonstrated in Figure 5, which shows the first time derivative of the east component at the Hermanus Observatory in South Africa for the past 10 years.

It is obvious that the field variation as monitored by an observatory such as Hermanus is much more structured than what can be modeled using a low-order Taylor expansion, especially if several years are considered. In particular, the existence of so-called geomagnetic jerks (e.g., Mandea et al. 2010), which are abrupt changes in the secular variation trend, hampers a description of the field variation by Taylor expansion in time. Jerk signatures at Hermanus are seen around 2007 and (less pronounced) around 2005. Jerks have been extensively studied with ground data, but the rather coarse spatial distribution of the observatory network hampers a determination of the global distribution of jerks; therefore, satellites provide an excellent opportunity to study these interesting events of rapid core field changes.

B-splines offer a better way of describing core field dynamics compared with a Taylor expansion and have been used for modeling core field changes with only ground observations (e.g., Bloxham \& Jackson 1992). A temporal parameterization by splines has also been used for the various versions of the Comprehensive Model (Sabaka et al. 2002, 2004), which are derived by joint analysis of ground observatory and satellite data spanning several decades.

Examples of recent spline models that are derived from the satellite data of the past decade are the models of Olsen et al. (2006b), Lesur et al. (2010), and Olsen et al. (2011) (Figure 5). It is obvious that the ability of the models to describe rapid core field changes improves as more and more 


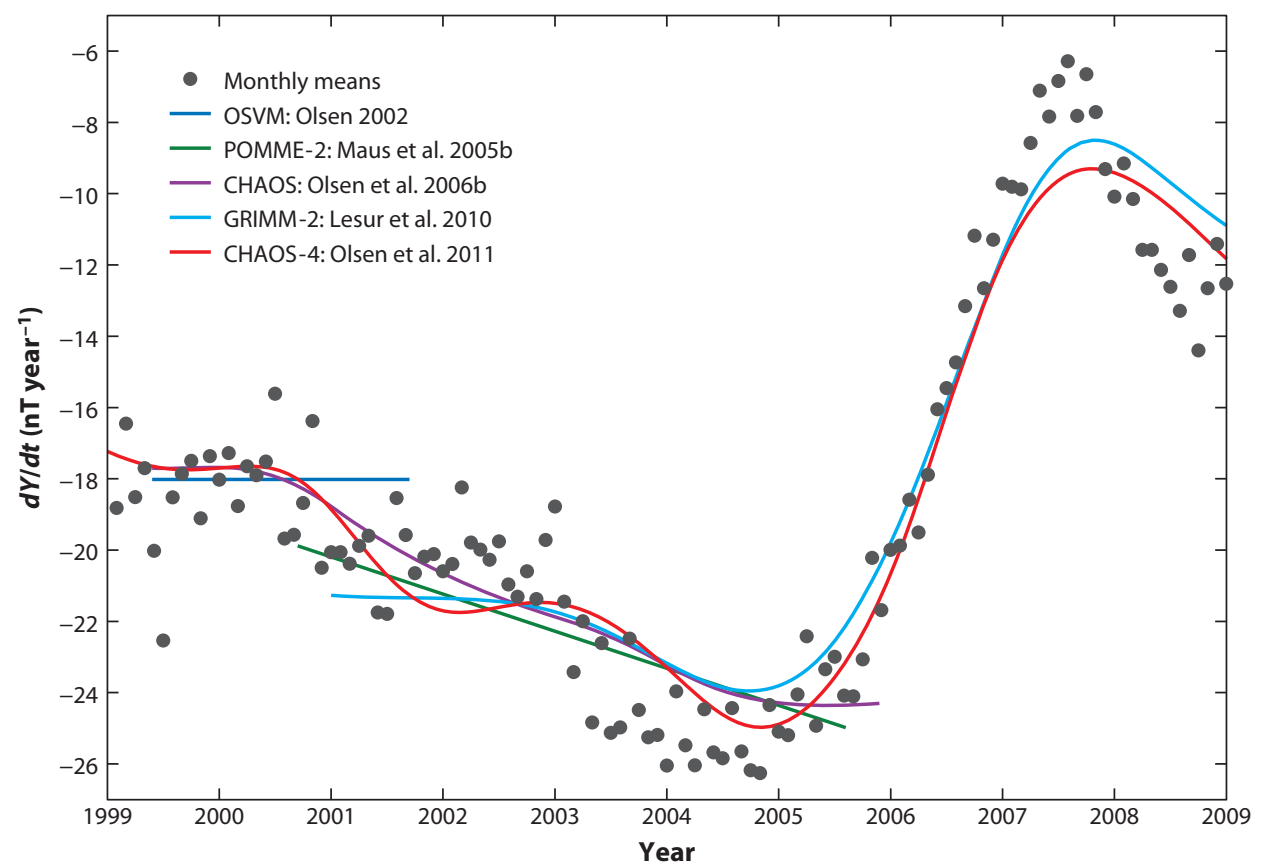

Figure 5

First time derivative of the east component in the geomagnetic frame at the Hermanus Observatory in South Africa. Symbols refer to observations (annual difference of monthly means), whereas the solid curves indicate model values. The gray circles represent the annual difference of monthly means as observed at Hermanus, whereas the dark blue line shows the field variation as given by the OSVM model of Olsen (2002). This model was derived from Ørsted satellite data spanning two years (as indicated by the length of the line) and describes the static part of the geomagnetic field up to $n=29$ and its linear time dependence up to $n=13$. Maus et al. (2005b) also estimated a quadratic time dependence using five years of Ørsted and CHAMP data; the corresponding model values for Hermanus are shown by the green line. Time dependence of the other three models (CHAOS, GRIMM, and CHAOS-4) is described by splines. Abbreviation: nT, nanotesla.

satellite data become available. The models also benefit from the use of splines (models CHAOS, GRIMM-2, and CHAOS-4) as opposed to a Taylor expansion (models OSVM and POMME-2) to describe the time dependence of the Gauss coefficients. This better spatial resolution of the recent secular variation models has been used to derive small-scale features of core flow; examples are given by Gillet et al. (2007), Holme \& Olsen (2006), Olsen \& Mandea (2008), Pais \& Jault (2008), and Holme et al. (2011).

In addition to obtaining global models of rapid core field changes, satellite data have also been used to determine field variations with high spatial resolution of the first time derivative (linear secular variation). For the assessment, it is useful to look at the spatial power spectrum of the first time derivatives [see Equation (1), but note that the spatial power spectrum is calculated from the first time derivative, $\dot{g}_{n}^{m}, \dot{b}_{n}^{m}$, of the Gauss coefficients]. Figure 6 shows the spectrum as obtained from six months of Magsat satellite data (Langel \& Estes 1985b). Only coefficients up to $n=6$ are above the noise level, indicated by the flat part of the spectrum at approximately $70\left(\mathrm{nT}_{\text {year }}{ }^{-1}\right)^{2}$. Additional use of data from the Dynamics Explorer 2 (DE-2) satellite between September 1981 and January 1983 improves the secular variation determination slightly and reduces the noise level to approximately $30\left(\text { nT }^{\text {Tear }}{ }^{-1}\right)^{2}$ (Langel et al. 1988). A major improvement was possible by analyzing the first two years of Ørsted observations, which reduced the noise level to approximately 1 


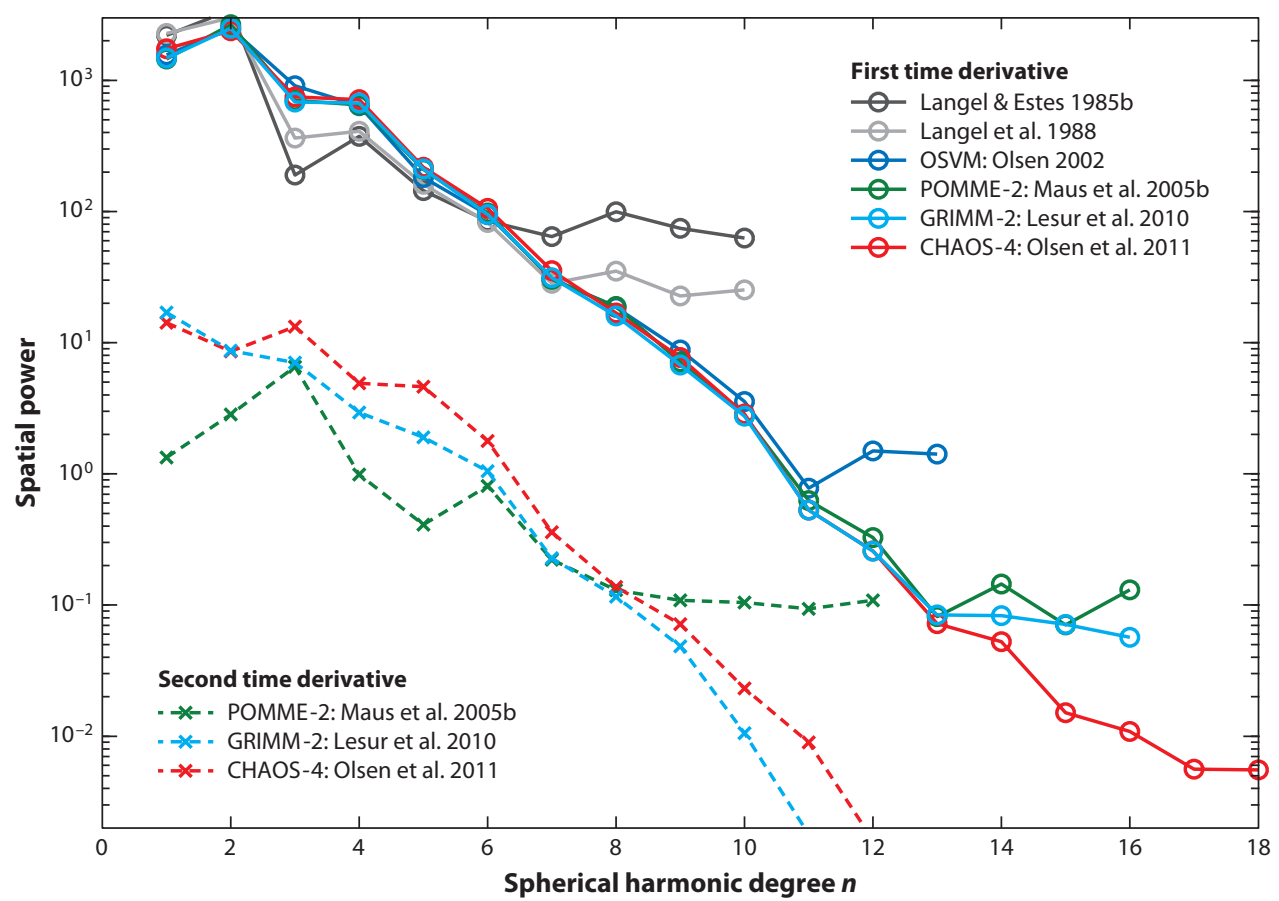

Figure 6

Spatial spectra of first time derivative [secular variation, solid curves, in (nT year $\left.{ }^{-1}\right)^{2}$ ] and second time derivative [secular acceleration, dashed curves, in $\left(\mathrm{nT} \mathrm{year}^{-2}\right)^{2}$ ] of the core field for various magnetic field models, at Earth's surface. Abbreviation: nT, nanotesla.

$\left(\mathrm{nT} \mathrm{year}^{-1}\right)^{2}$ (Olsen 2002); first time derivative coefficients up to $n=11$ are resolved by the OSVM model. Yet another order of magnitude in noise reduction was obtained by Maus et al. (2005b) in their combined analysis of Ørsted and CHAMP data spanning more than five years, resulting in a determination of the first time derivative up to $n=13$. The model of Lesur et al. (2010) has a similar noise level. Finally, the first time derivative of the model CHAOS-4 (Olsen et al. 2011) has a noise level as low as $0.02\left(\mathrm{nT}_{\mathrm{T}} \mathrm{ear}^{-1}\right)^{2}$. This allows determination of secular variation for spatial scales up to $n=15$. These models, however, describe the mean secular variation averaged over several years (because they were determined using temporal regularization), which, at least for the higher degrees, is probably different from the instantaneous secular variation.

Also presented in Figure 6 are spectra of the second time derivative (secular acceleration) for various field models. There are considerable differences between the secular acceleration as given by the various models, which are probably due to the different modeling approaches, especially regarding model regularization in time, as discussed, for example, by Lesur et al. (2011).

As shown in Figure 3, the crustal field dominates the core field for spherical harmonic degrees above $n=13$, and it is therefore not possible to infer small-scale structures of the (static) core field. However, because the crustal field is time independent (on the timescales considered here), the time change of the core field is, in principle, observable at all spatial wavelengths. Figure 6 demonstrates that with the recent core field models, it is possible to infer the time change (secular variation) of the core field down to scales smaller $(2,670-\mathrm{km}$ lengths at the surface, corresponding to $n=15$ ) than the scales of the (static) core field itself. 


\subsection{Crustal Field}

Early models of the crustal field as seen from space have been published, for example, by Cain et al. (1984, 1989), Cohen \& Achache (1990), and Regan et al. (1975); see Langel \& Hinze (1998) for a review of crustal field models derived from satellite observations before CHAMP. More recently, Thébault et al. (2010) reviewed the various techniques in use for modeling the crustal field and the obtained results.

Crucial for a good determination of the crustal field is the proper accounting for external field variations during the data analysis. Unfortunately, the obtained results depend somewhat on the processing approach. As described by Thébault et al. (2010), two complementary philosophies are in use for deriving spherical harmonic models of Earth's crustal field: In the sequential approach, a priori models of all known magnetic field contributions but the crustal field are subtracted from the data, followed by careful data selection and application of empirical corrections. Contrary to this sequential approach, the comprehensive approach aims to solve simultaneously for all major internal and external field contributions.

Similar to the spatial power spectra of the secular variation presented in Figure 6, spectra of various crustal field models are shown in Figure 7. The model of Cain et al. (1989) is derived from Magsat satellite data using a rather simple treatment of external sources, which resulted in a leakage of external field signals into the crustal field model, as indicated by the rather high power of that model. In contrast, Cohen \& Achache (1990), who also used Magsat satellite data, removed external fields by high-pass filtering of the data. Because this approach also removes part of the crustal signal (see, e.g., Thébault et al. 2012), the resulting model has rather weak power. The difference in the power of these two models may be regarded as an indicator of the uncertainty of crustal field models derived from the early satellite missions POGO and Magsat.

Let us now look at the first crustal models that include data from the recent satellites (and especially from CHAMP, the low altitude of which is essential for a good determination of the crustal field). The model of Sabaka et al. (2004), derived using the comprehensive approach by

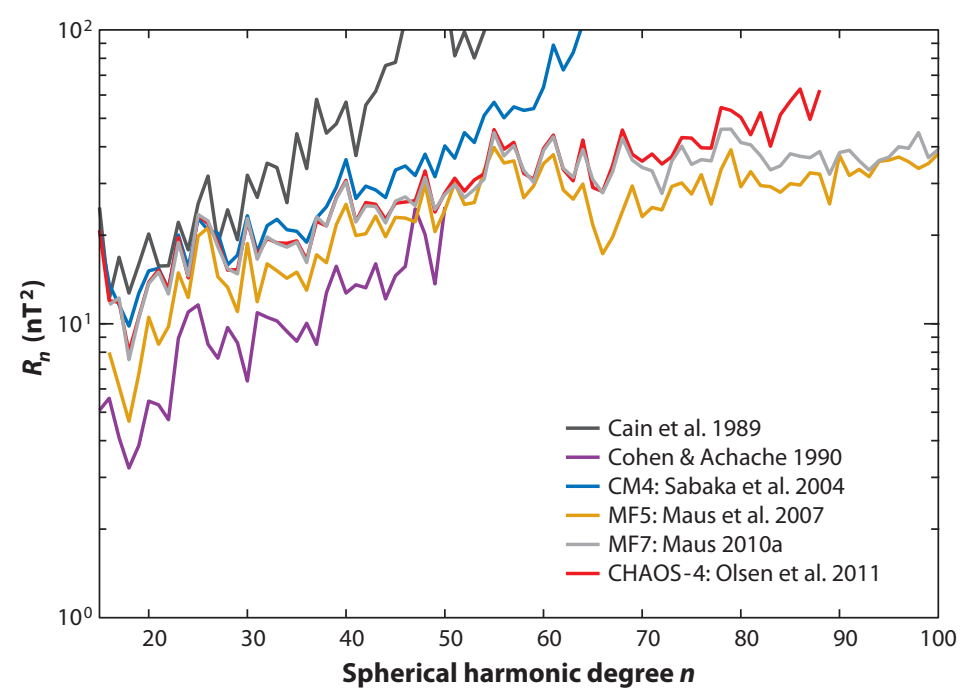

Figure 7

Spatial spectra of the crustal field for various magnetic field models, at Earth's surface. Abbreviation: nT, nanotesla. 
Sq: solar quiet daily magnetic variation coestimation of internal and external fields, yields power that is considerably reduced compared with that of Cain et al. (1989). Similarly, the MF5 model of Maus et al. (2007), derived by trackby-track high-pass filtering of CHAMP data, has power that is considerably higher than that of the model of Cohen \& Achache (1990) (but still too low, compared with more recent models).

The most recent field models, derived from the latest CHAMP data (which were sampled at altitudes below $300 \mathrm{~km}$ a few months before atmospheric reentry of the satellite), are in rather good agreement, at least up to spherical harmonic degree $n=80$ or so. This is indicated by the fact that the power of the models of Olsen et al. (2011) and Maus (2010a) almost coincide.

In the near future, data from the three-satellite constellation Swarm are expected to significantly improve the spatial resolution of crustal field models. The two lower Swarm satellites will, for the first time, allow not only the observation of the magnetic field vector but also an estimate of the east-west gradient of the magnetic field. This results in enhanced resolution. By analysis of synthetic magnetic field data from a full mission simulation, it could be demonstrated that crustal fields up to degree $n=133$ or even $n=150$ are obtainable (e.g., Olsen et al. 2006a, TøffnerClausen et al. 2010), bridging the existing gap between satellite models and data from ground, airborne, and marine surveys.

\subsection{Electrical Conductivity of the Mantle}

Temporal variations of the magnetic field produce induced currents in Earth's interior regardless of whether the variations are of internal origin (due to the variations of the core field) or of external origin (caused by electrical currents in the ionosphere and magnetosphere). Observations of the total magnetic field variation [i.e., the superposition of the primary (inducing) field and of the secondary field caused by the induced electrical currents] allow for a determination of the electrical conductivity of Earth's interior.

Probing the conductivity of the mantle using core field variations requires a precise determination of the field during rapid and isolated events such as geomagnetic jerks and some a priori assumptions about the kinematics of the fluid motion at the top of the core. This approach has its strength in providing an upper bound of the conductivity of the deep mantle. Probing mantle conductivity down to depths of $\sim 1,200 \mathrm{~km}$ is possible by analyzing magnetic field variations of external origin. Both approaches require good knowledge of the time-space structure of the inducing field, which can be obtained with ground observatory data and/or with satellite magnetic field observations. A review of the various methods that can be used for electromagnetic induction studies with satellites, along with results obtained with the satellites POGO and Magsat, is given by Olsen (1999a). Constable (2007) and Kuvshinov (2011) provide more recent reviews of the topic.

The launches of the Ørsted and CHAMP satellites resulted in increased interest in probing mantle conductivity from space, and various conductivity models have been derived (e.g., Kuvshinov \& Olsen 2006, Velímsky 2010). Only magnetospheric currents are of external origin, as seen by a satellite; the ionospheric $E$-region currents that are responsible for the solar quiet daily magnetic variation $(\mathrm{Sq})$ (which is a source often used for induction studies using groundbased data) are below the satellite and hence of internal origin. This hampers the determination of mantle conductivity; therefore, the main source for induction studies from space is the magnetospheric ring current (see Section 3.1). Its source geometry is assumed to be given by the spherical harmonic $P_{1}^{0}$ (using dipole coordinates $\theta_{d}, \phi_{d}$ ), so Equation (1b) reduces to

$$
V_{\mathrm{ext}}(t)=a \varepsilon_{1}^{0}(t)\left(\frac{r}{a}\right) \cos \theta_{d}
$$


If the conductivity of Earth's interior depends only on radius (1D conductivity), each external (inducing) spherical harmonic coefficient induces only one internal coefficient (of same degree $n$ and order $m$ ); in this case, the potential of the induced part is given by

$$
V_{\text {int }}(t)=a \iota_{1}^{0}(t)\left(\frac{a}{r}\right)^{2} \cos \theta_{d} .
$$

However, in the general case of $3 \mathrm{D}$ conductivity (which means that conductivity changes in radial direction as well as in lateral direction), one external coefficient induces all internal coefficients. Therefore, the corresponding induced potential is

$$
V_{\mathrm{int}}(t)=a \sum_{n, m} \iota_{n}^{m}(t)\left(\frac{a}{r}\right)^{n+1} P_{n}^{m}\left(\cos \theta_{d}\right) \exp i m \phi_{d} .
$$

Until now, only 1D conductivity models have been derived from satellite data [using Equations (3a) and (3b)], treating the magnetic field observations either in the frequency domain or in the time domain.

Kuvshinov \& Olsen (2006) used the frequency domain approach. Fourier transformation of the time series $\varepsilon_{1}^{0}(t)$ and $\iota_{1}^{0}(t)$ allows for an estimation of the transfer function $Q(\omega)=\hat{\iota}_{1}^{0}(\omega) / \hat{\varepsilon}_{1}^{0}(\omega)$ between internal (induced) and external (inducing) coefficients. Using Ørsted, CHAMP, and SACC data between 2001 and 2005, Kuvshinov \& Olsen (2006) determined $Q(\omega)$ for frequencies $\omega$ corresponding to periods between $14 \mathrm{~h}$ and 14 months and derived a $1 \mathrm{D}$ mantle conductivity model from this transfer function. The obtained model is shown in Figure 8.

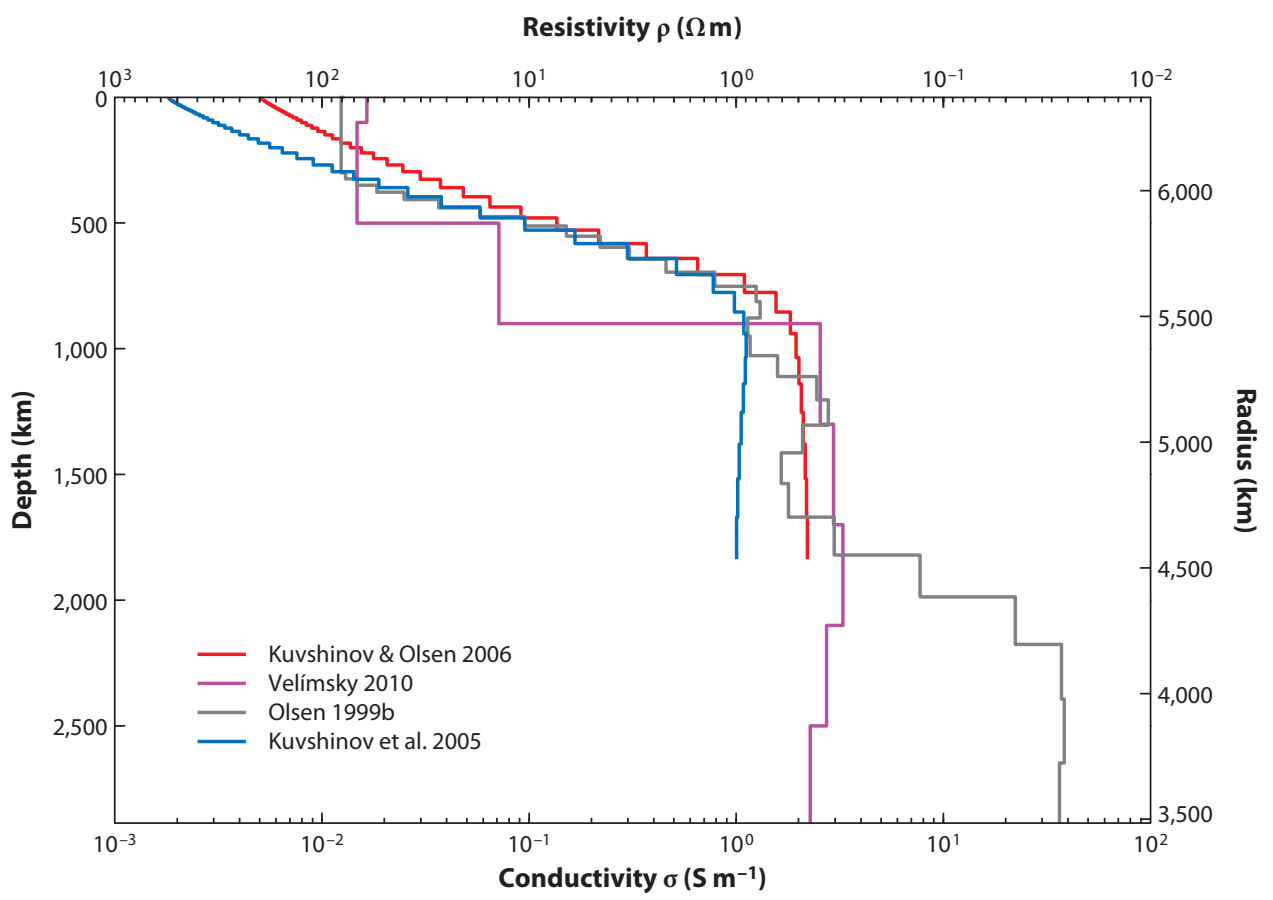

Figure 8

1D conductivity models for Earth's mantle. The models of Kuvshinov \& Olsen (2006) (red) and Velímsky (2010) (magenta) are global models determined from recent satellite data, whereas those of Olsen (1999b) (gray) and Kuvshinov et al. (2005) (blue) are determined from ground data. 
Dst index: magnetic disturbance storm time index monitoring the strength of the magnetospheric ring current
The first inversion of satellite data in the time domain was done by Velímsky et al. (2006). More recently, Velímsky (2010) used CHAMP vector data from 2001 to 2007 and estimated time series of the external coefficient $\varepsilon_{1}^{0}(t)$ as well as of the corresponding induced coefficient $\iota_{1}^{0}(t)$. Synthetic values $\iota_{1, s}^{0}(t)$ of the induced coefficient were calculated from the observed external coefficient $\varepsilon_{1}^{0}(t)$ plus a $1 \mathrm{D}$ mantle conductivity model and subsequently compared with the observed induced coefficient $\iota_{1}^{0}(t)$. An optimal 1D conductivity model was found by minimizing the average misfit of the difference between observed and synthetic values of the induced coefficient. The result of this approach is shown in Figure 8. For comparison, two conductivity models derived from ground data are also shown: The model of Olsen (1999b) is derived from European observatories, whereas that of Kuvshinov et al. (2005) is obtained from observatory and submarine cable measurements in the Northern Pacific. There is relatively good agreement among all models at depths between 800 and $1,800 \mathrm{~km}$, a region that is sensed by external field variations of periods between a few days and one year. Differences at shallower depths, especially regarding the satellite-based model of Velímsky (2010), are probably due to contamination by ionospheric daily signals (which hamper the use of satellite data for induction studies).

Also, regarding mantle conductivity, it is expected that the upcoming Swarm satellite mission will lead to a major advance. Simultaneous data from all three satellites will allow for a better determination of the time-space structure of magnetospheric and induced contributions, with the potential of resolving 3D mantle conductivity from space. Experiments using synthetic data (e.g., Kuvshinov et al. 2006) are encouraging and demonstrate the capability of the developed approaches.

\section{IONOSPHERE AND MAGNETOSPHERE}

The novelty in investigating ionospheric and magnetospheric currents with high-precision magnetic satellites is mainly twofold:

- Measurements from high-precision magnetic satellites allow for a precise determination of weak field contributions to the different vector components of the magnetic field.

- Removing the core, crustal, and magnetospheric contributions, as given by high-quality field models, enables the identification of processes with comparable small amplitude (of only few nanotesla).

This section highlights both recent findings that are of interest for improving core and crustal field models and new results in ionospheric and magnetospheric research.

\subsection{Magnetospheric Currents}

The main magnetospheric current systems that contribute to the near-Earth magnetic field are the Chapman-Ferraro currents flowing at the dayside on the magnetopause, the tail currents on the nightside, and the ring current in the equatorial plane. These magnetospheric current systems, and their connection to the polar ionosphere via FACs, are discussed, for example, in Kivelson \& Russell (1995). Figure $4 \boldsymbol{c}, \boldsymbol{d}$ displays a magnetospheric contribution of approximately $20 \mathrm{nT}$ for a geomagnetically quiet day, but during disturbed conditions-for example, during a geomagnetic storm-the ring current is intensified and the magnetic field disturbance may reach values of hundreds of nanotesla.

The strength of the magnetospheric ring current is monitored by the Dst index that was introduced by Sugiura (1964). It is routinely determined from data of four ground observatories and is available from the World Data Center Kyoto (http://wdc.kugi.kyoto-u.ac.jp/dstdir/). The baseline of Dst is, roughly speaking, determined such that its time average over geomagnetically 
quiet periods is zero. However, the magnetospheric ring current does not vanish during quiet conditions; there are magnetospheric contributions even for Dst $=0$. This offset in Dst can be determined only with high-precision LEO satellites. Although magnetic intensity data taken by the POGO satellites have been used to determine this quiet-time level of $D s t$, its reliable determination of approximately $20 \mathrm{nT}$ was not possible until the availability of vector satellite observations from Magsat (Langel \& Estes 1985a,b; Langel et al. 1980).

An analysis of the time-space structure of the large-scale magnetospheric field was performed by Maus \& Lühr (2005) on the basis of five years of Ørsted and CHAMP observations between 1999 and 2004. They separated the different magnetospheric current systems by selecting appropriate coordinate systems: The inner magnetosphere including the ring current is strongly coupled to Earth's dipole field and therefore best described in the solar-magnetic coordinate frame (SM frame), which is aligned with the geomagnetic dipole axis. In contrast, currents of the distant magnetosphere-for example, the tail current—are best described in the geocentric-solarmagnetospheric coordinate frame (GSM frame), which is fixed to the direction to the sun (see, e.g., Kivelson \& Russell 1995 for a description of the different coordinate frames). Maus \& Lühr (2005) found a constant quiet-time magnetic field in the GSM frame of approximately $13 \mathrm{nT}$, which they attribute to tail currents. They also found a constant field of approximately $8 \mathrm{nT}$ in the SM frame (which, together with the constant field in the GSM frame, yields the $\sim 20 \mathrm{nT}$ that was found earlier by Langel and coworkers).

In a subsequent study, Lühr \& Maus (2010) used nine years of Ørsted and CHAMP observations between 2000 and 2009 to investigate the solar cycle dependence of the quiet-time magnetospheric field. They suggest that contributions in the GSM frame are mainly due to magnetotail currents, whereas the dayside magnetopause currents follow the SM frame. Contributions from the GSM frame seem to have no solar cycle dependence, but the SM field was found to depend strongly on the solar cycle, varying between $0 \mathrm{n}$ T during low solar flux and $15 \mathrm{n}$ T for high solar flux. Lühr \& Maus (2010) also suggest the possibility that the quiet-time ring current completely vanishes for very low solar flux conditions.

In addition to determination of the quiet-time level of magnetospheric fields, their variability with geomagnetic activity has been investigated using satellite data. Langel \& Estes (1985b) determined a linear regression coefficient between the external coefficient $q_{1}^{0}$ [see Equation (1)] and the Dst index of -0.69 ; similar values were found by the first Ørsted field models (Olsen 2002, for instance, determined a value of -0.64). However, Dst monitors not only the magnetospheric ring current but also contributions from its Earth-induced counterpart (the negative sign of the regression coefficient is due to the fact that Dst measures the strength of the magnetic North component at the equator, which is given by $-q_{1}^{0}$ if induced effects are ignored). Maus \& Weidelt (2004) and Olsen et al. (2005) decomposed Dst into its magnetospheric part, Est, and its induced part, Ist $(D s t=E s t+I s t)$. Using Est rather than Dst to describe the variability of $q_{1}^{0}$ leads to a regression coefficient that is closer to unity [Maus \& Lühr (2005) found a value of -0.79] but still significantly different from the expected value of -1 . It is an open question why the magnetospheric field as monitored by LEO satellites is only $80 \%$ of that found with ground observations. Whether this is due to the scheme used to derive Dst (resulting in values that are too large) or whether a part of the signal that is monitored by Dst is caused by an additional current in the ionosphere is still an unsolved issue.

\subsection{Ionospheric Currents}

The ionospheric current systems that are considered in this review are sketched in Figure 2, whereas their amplitudes and spatial scales are given in Figure 3. At low latitudes, the EEJ,
SM frame: solar-magnetic coordinate frame GSM frame: geocentric-solarmagnetospheric coordinate frame 
IHFAC:

interhemispheric field-aligned current

Polar electrojet (PEJ): horizontal electric current flowing in the auroral E-region ionosphere the meridional current system centered at the dip equator, and the plasma bubbles play a role. Sq current vortexes in the $E$-region of both hemispheres, and the connecting interhemispheric field-aligned currents (IHFACs), contribute to the magnetic field at middle latitudes. The polar ionosphere is dominated by polar electrojets (PEJs) and FACs connecting them to the magnetosphere. Most of these currents have magnetic signals that are visible even on single orbits, although some current systems (e.g., Sq and EEJ) vanish during the night (see Figure $4 e, f$ ).

3.2.1. Mid-latitude Sq and interhemispheric field-aligned currents. The dayside ionospheric current systems Sq and EEJ are caused by the ionospheric dynamo. Thermospheric tidal winds move plasma through the field lines of the ambient magnetic field, thereby generating electrical currents, which, in turn, produce a magnetic field. Depending on the altitude and conditions of the process, it is common to distinguish between an $E$-region dynamo and an $F$-region dynamo (e.g., Heelis 2004, Kelley 2009, Rishbeth 1997).

The $E$-region current system consists of two vortexes centered around local noon at $\pm 30^{\circ}$ latitude, with anticlockwise (clockwise) currents in the Northern (Southern) Hemisphere. Their global extension and variability have been studied using satellite data by Sabaka et al. (2004) and Pedatella et al. (2011).

Owing to seasonal differences in wind and ionospheric conductivity, there is a winter-summer hemispheric asymmetry of current vortex strength (e.g., Fukushima 1994), which produces an interhemispheric electrostatic potential difference. This drives IHFACs from the summer to the winter hemisphere in the dawn sector, and in the opposite direction in the noon and dusk sectors. IHFACs were first proposed by van Sabben $(1966,1970)$, and although some attempts have been made to detect them from ground (e.g., Fukushima 1994, van Sabben 1966), the first unambiguous determination was achieved by Olsen (1997) using Magsat satellite data. He found a direction and density of the IHFACs that are in agreement with the theoretical predictions for winter months: from north to south in the evening sector and vice versa in the morning sector, with current densities of $2-4 \mathrm{nA} \cdot \mathrm{m}^{-2}$. Owing to the asymmetry between the magnetic and geographic equators, IHFACs do not vanish during equinox (when the two current vortexes are almost symmetric); this theoretical result was also confirmed by Olsen (1997).

Park et al. (2011) investigated IHFACs using nine years of CHAMP observations between 2000 and 2009 and determined the climatology of their longitudinal, LT, and seasonal variations. In agreement with previous findings by Yamashita \& Iyemori (2002) (who investigated IHFACs with Ørsted data), they found that dusk-side IHFACs are directed from north to south irrespective of season, which, however, is not consistent with the currently accepted theory (Fukushima 1994). Park et al. (2011) also observed an enhanced southward component of the noontime IHFACs near the South Atlantic Anomaly. They explain this with the weak core field in this region, which enhances the $E$-region currents by shifting the effective dynamo layer toward higher altitudes with stronger winds and higher plasma density (Takeda 1996).

3.2.2. Equatorial electrojet. The EEJ is a band of intense electric currents flowing along the magnetic dip equator in the ionospheric $E$-region. It is controlled by the $E$-region dynamo, the ionospheric conductivity, and the special geometry of the geomagnetic field (e.g., Heelis 2004). The EEJ is a dayside phenomenon with an amplitude maximum at 11-12 LT. It has been investigated from the ground for several decades, but its global extension can be studied only with LEO satellites. Ivers et al. (2003) and Lühr et al. (2004) analyzed Ørsted and CHAMP data, respectively, and found that the eastward currents of the EEJ are confined to $\pm 2^{\circ}$ QD latitude, whereas westward-directed return currents peak at approximately $\pm 5^{\circ}$. Manoj et al. (2006) revealed a short longitudinal correlation length of the EEJ of $\pm 15^{\circ}$ in CHAMP data, which is 
believed to be similar to that of the dynamo action and/or of the conductivity. Alken \& Maus (2007) used Ørsted, SAC-C, and CHAMP data to derive a climatological model (available at http://www.geomag.org/models/EEJ.html) of the EEJ sheet current density.

Monitoring of the EEJ has been crucial, for example, for the investigation of the coupling between the lower and upper atmospheres. This has been a hot topic during the last years of the extended minimum of solar cycle 23, when the atmospheric influence on ionospheric electrodynamics and structure is better detectable owing to the very low plasma densities. England et al. (2006) and Lühr et al. (2008) revealed the existence of wave structures in the EEJ (and thereby in the $E$-region dynamo), which they attribute to upward-propagating atmospheric waves (Oberheide et al. 2009). Fejer et al. (2010) investigated the longitudinal variation of the ionospheric response to sudden stratospheric warming in ground and CHAMP satellite data and identified their dependence on the phase of the moon.

3.2.3. Meridional current system in the low-latitude $F$-region. In the low-latitude $F$-region, a meridional current system exists as a result of wind-driven electrodynamics (Heelis 2004): At the dip equator, currents are upward directed from the $E$ - to the $F$-region. They then flow along magnetic field lines poleward and downward to the $E$-region, where the current system is closed by horizontal currents directed toward the dip equator.

These low-latitude $F$-region currents were found in Magsat dusk magnetic data, but no signal was detected during dawn (e.g., Langel et al. 1993, Maeda et al. 1982). Olsen (1997) confirmed this result and also revealed a lunar tidal contribution in the dusk current system.

An investigation of the full LT dependence of the low-latitude meridional currents was possible with CHAMP satellite data. Lühr \& Maus (2006) found upward currents between 17 LT and 20 LT and downward currents around noon. Subsequently, Park et al. (2010) revealed a longitudinal variation of the downward currents around noon that is anticorrelated with the strength of the ambient magnetic field (e.g., stronger currents in the South Atlantic Anomaly), but they could not confirm such behavior for dusk. They also identified wave structures during noon similar to tropospheric waves propagating upward into the ionosphere, but again no corresponding structure was found during dusk. These findings suggest that the effect of $E$-region electrodynamics dominates in the dayside $F$-region.

3.2.4. Equatorial plasma irregularities. Equatorial plasma irregularities, also known as Spread$F$ or equatorial plasma bubbles, are flux tubes of depleted plasma density that occur regularly in the evening ionosphere. They are formed at low latitudes at the bottom of the $F$-region, rise upward, and finally expand poleward. Apex altitudes (during geomagnetically quiet conditions) are up to $700 \mathrm{~km}$, corresponding to a footprint of the flux tube below $30^{\circ}$ magnetic latitude. A review including concise theoretical descriptions of the phenomenon is provided in chapter 4 of Kelley (2009).

Equatorial plasma irregularities are detectable with satellite magnetic field data because they produce a diamagnetic current density

$$
\mathbf{j}_{d}=-k \frac{\nabla\left(n_{e} T\right) \times \mathbf{B}}{|\mathbf{B}|^{2}},
$$

directed along the gradient of plasma density $n_{e}$ multiplied by the sum $T=T_{e}+T_{i}$ of ion and electron temperature. Here, $k$ is the Boltzmann constant and $\mathbf{B}$ is the ambient magnetic field vector.

Lühr et al. (2002) took advantage of the low altitude of the CHAMP satellite to study plasma irregularities and their magnetic effect. The results of the comprehensive climatology of their 
EIA: Equatorial Ionization Anomaly, also termed the Appleton Anomaly diamagnetic signatures derived by Stolle et al. (2006) are in rough agreement with findings from plasma depletions (e.g., Huang et al. 2001, Xiong et al. 2010). In the South American region, for example, plasma irregularities occur almost every evening during late September and December but are nearly absent in June. The magnetic signatures of plasma irregularities depend on solar flux and satellite altitude: At altitudes of approximately $350 \mathrm{~km}$ (CHAMP), they are seldom in years of low solar activity, whereas at 700-km altitude (Ørsted), they seem to be absent at any solar flux level.

Concentrating on magnetic signatures perpendicular to the ambient field, Park et al. (2009) provided a comprehensive climatology of FACs flowing along the flux tubes. Their results suggest a poleward-directed Poynting flux of early evening events, but no clear preferred direction could be found for night events. The seeding and growing mechanisms of equatorial plasma bubbles constitutes an ongoing topic in physical modeling of the ionosphere (e.g., Huba et al. 2011), and comparing the model results with the observations will certainly advance the understanding of plasma irregularities.

3.2.5. Large-scale pressure gradient-driven currents. The diamagnetic effect applies also to larger-scale regions with plasma density gradients. The Equatorial Ionization Anomaly (EIA), or Appleton Anomaly, for instance, is characterized by a plasma density trough at the magnetic equator and bands of enhanced plasma density at approximately $\pm 15^{\circ}$ QD latitude (e.g., Kelley 2009). The EIA develops after sunrise, with a first maximum shortly after noon and a second one just after sunset. Lühr et al. (2003) demonstrated that the EIA leads to a systematic depression of the magnetic field intensity measured by CHAMP at the peak latitude of the EIA. The effect is shown in Figure $4 f$ as a depression of approximately $5 \mathrm{nT}$ at magnetic latitudes of approximately $\pm 10^{\circ}$.

\subsubsection{Gravity-driven currents. The gravity-driven current density}

$$
\mathbf{j}_{g}=n_{e} m_{i} \frac{\mathbf{g} \times \mathbf{B}}{|\mathbf{B}|^{2}}
$$

(where $m_{i}$ is ion mass and $\mathbf{g}$ is Earth's gravity vector) is particularly intense in the low-latitude ionosphere, where $\mathbf{g}$ is perpendicular to the (mainly horizontal) ambient magnetic field $\mathbf{B}$. Because the currents depend also on plasma density $n_{e}$, they are expected to be largest at the $F$-region density peak at approximately 300-km altitude. Observational evidence of gravity-driven currents in CHAMP data was found by Maus \& Lühr (2006). They identified an eastward-flowing current band of approximately $60^{\circ}$ latitudinal extension centered at the equator but moving northward (southward) during northern summer (winter). The authors estimated a height-integrated current density of approximately $7 \mathrm{~mA} \mathrm{~m}^{-1}$, a total eastward current of up to $50 \mathrm{kA}$, and a magnetic signature of up to $6 \mathrm{nT}$.

3.2.7. Currents in the polar ionosphere. Complicated current systems exist in the polar regions. They are particularly strong during times of enhanced energy transfer from the sun into the magnetosphere but are always present, even during geomagnetically quiet times and in darkness (winter). When selecting data for core and crustal field modeling, it is therefore difficult to avoid contributions from polar currents by applying the same data selection criteria as for nonpolar latitudes (e.g., data from dark regions and geomagnetically quiet conditions). A better understanding of polar ionospheric currents is therefore critical for improved modeling of the internal field.

LEO satellites have been used to determine the horizontal currents in the auroral E-region (PEJs) and the corresponding FACs that feed the ionospheric currents by coupling to the 
magnetosphere. The seasonal variation of FACs for solar minimum years, and their dependence on the interplanetary magnetic field, was investigated by Christiansen et al. (2002) on the basis of vector data from Magsat and Ørsted.

Olsen (1996) studied the strength and location of the PEJs with Magsat data by fitting a model consisting of a series of line currents to residuals of the magnetic field intensity (after subtraction of the core and crustal fields). This method was subsequently applied by Ritter et al. (2004) to two years of CHAMP magnetic intensity data to determine the climatology of ionospheric horizontal currents for geomagnetically quiet conditions.

Juusola et al. (2009) describe a spherical line current approach that consistently models the magnetic signature of the horizontal currents as well as the corresponding FACs. They applied their method to CHAMP observations between 2001 and 2005 and found that the merging electric field at the magnetopause, $E_{m}$, is the most suitable parameter to describe the intensity and location of the currents-and thus confirm the usefulness of selecting polar data according to the strength of $E_{m}$ when modeling the core and crustal fields (e.g., Olsen et al. 2006b).

\section{CONCLUSIONS}

During the past decade, considerable progress has been obtained in modeling and understanding the various contributions to the geomagnetic field, thanks to the high-precision magnetic field measurements that are taken by LEO satellites. More than 10 years of continuous observations from space enabled the study of core field dynamics and crustal field magnetization with unprecedented resolution in space and time. The three-satellite constellation mission Swarm, scheduled for launch in 2012, will continue to monitor the field from space. Swarm is the most ambitious project so far regarding accurate measurements of Earth's magnetic field, and the desired magnetic field accuracy is significantly higher than that of all previous missions.

Although the primary science objective of all high-precision satellites is mapping of Earth's internal magnetic field, these missions also provide significant advances in ionosphere/thermosphere research. This has been in particular true for the CHAMP satellite owing to its low altitude, its long lifetime, and its extended payload that also allows for measuring plasma parameters and thermospheric density and winds (Lühr et al. 2011). All these parameters, and in addition the electric field, will also be measured by the Swarm mission; these measurements, together with the constellation aspect of Swarm, are exciting for external field studies. The two side-by-side flying lower satellites will, for instance, allow for the first time an in situ determination of FACs (Ritter \& Lühr 2006) without the assumptions about current geometry that have to be made for processing single-satellite data.

\section{DISCLOSURE STATEMENT}

The authors are not aware of any affiliations, memberships, funding, or financial holdings that might be perceived as affecting the objectivity of this review.

\section{LITERATURE CITED}

Alken P, Maus S. 2007. Spatio-temporal characterization of the equatorial electrojet from CHAMP, Ørsted, and SAC-C satellite magnetic measurements. F. Geophys. Res. 112:A09305

Backus G. 1986. Poloidal and toroidal fields in geomagnetic field modeling. Rev. Geophys. 24:75-109

Backus GE. 1970. Non-uniqueness of the external geomagnetic field determined by surface intensity measurements. 7. Geophys. Res. 75:6339-41 
Bloxham J, Jackson A. 1992. Time-dependent mapping of the magnetic field at the core-mantle boundary. 7. Geophys. Res. 97:19537-63

Cain JC. 2007. POGO (OGO-2, -4 and -6 spacecraft). See Gubbins \& Herrero-Bervera 2007, pp. 828-29

Cain JC, Hendricks SJ, Langel RA, Hudson WV. 1967. A proposed model for the International Geomagnetic Reference Field-1965. 7. Geomagn. Geoelectr. 19:335-55

Cain JC, Schmitz DR, Muth L. 1984. Small-scale features in the Earth's magnetic field observed by Magsat. 7. Geophys. Res. 89:1070-76

Cain JC, Wang Z, Kluth C, Schmitz DR. 1989. Derivation of a geomagnetic model to $n=63$. Geophys. F. 97:431-41

Christiansen F, Papitashvili VO, Neubert T. 2002. Seasonal variations of high-latitude field-aligned currents inferred from Ørsted and Magsat observations. F. Geophys. Res. 107:1029

Cohen Y, Achache J. 1990. New global vector magnetic anomaly maps derived from Magsat data. F. Geophys. Res. 95:10783-800

Constable S. 2007. Induction from satellite data. See Gubbins \& Herrero-Bervera 2007, pp. 413-16

England S, Maus S, Immel T, Mende S. 2006. Longitudinal variation of the E-region electric fields caused by atmospheric tides. Geophys. Res. Lett. 33:L21105

Fejer BG, Olson ME, Chau JL, Stolle C, Lühr H, et al. 2010. Lunar dependent equatorial ionospheric electrodynamic effects during sudden stratospheric warmings. F. Geophys. Res. 115:A00G03

Friis-Christensen E, Lühr H, Hulot G. 2006. Swarm: A constellation to study the Earth's magnetic field. Earth Planets Space 58:351-58

Fukushima N. 1994. Some topics and historical episodes in geomagnetism and aeronomy. 7. Geophys. Res. 99:19,113-42

Gillet N, Jackson A, Finlay CC. 2007. Maximum entropy regularization of time-dependent geomagnetic field models. Geophys. F. Int. 171:1005-16

Gubbins D, Herrero-Bervera E, eds. 2007. Encyclopedia of Geomagnetism and Paleomagnetism. Heidelberg, Ger.: Springer

Heelis RA. 2004. Electrodynamics in the low and middle latitude ionosphere: a tutorial. 7. Atmos. Solar-Terr. Phys. 66:825-38

Holme R, Olsen N. 2006. Core-surface flow modelling from high-resolution secular variation. Geophys. 7. Int. 116:518-28

Holme R, Olsen N, Bairstow F. 2011. Mapping geomagnetic secular variation at the core-mantle boundary. Geophys. F. Int. 186:521-28

Huang CY, Burke WJ, Machuzak JS, Gentile LC, Sultan P. 2001. DMSP observations of equatorial plasma bubbles in the topside ionosphere near solar maximum. F. Geophys. Res. 106:8131-42

Huba J, Joyce G, Krall J. 2011. Three-dimensional modeling of equatorial spread F. In Aeronomy of the Earth's Atmosphere and Ionosphere, ed. MA Abdu, D Pancheva, IAGA Spec. Sopron Book Ser. 2:211-18. Dordrecht: Springer

Hulot G, Eymin C, Langlais B, Mandea M, Olsen N. 2002. Small-scale structure of the geodynamo inferred from Ørsted and Magsat satellite data. Nature 416:620-23

Hulot G, Sabaka TJ, Olsen N. 2007. The present field. In Treatise on Geophysics, ed. M Kono, 5:33-75. Amsterdam: Elsevier

Ivers D, Stening R, Turner J, Winch D. 2003. Equatorial electrojet from Ørsted scalar magnetic field observations. F. Geophys. Res. 108:1061

Juusola L, Kauristie K, Amm O, Ritter P. 2009. Statistical dependence of auroral ionospheric currents on solar wind and geomagnetic parameters from 5 years of CHAMP satellite data. Ann. Geophys. 27:1005-17

Kelley MC. 2009. The Earth's Ionosphere: Plasma Physics and Electrodynamics. San Diego, CA: Academic. 2nd ed.

Kivelson MG, Russell CT, eds. 1995. Introduction to Space Physics. Cambridge, UK: Cambridge Univ. Press

Kuvshinov A. 2011. Deep electromagnetic studies from land, sea, and space: progress status in the past 10 years. Surv. Geophys. 3:169-209

Kuvshinov AV, Olsen N. 2006. A global model of mantle conductivity derived from 5 years of CHAMP, Ørsted, and SAC-C magnetic data. Geophys. Res. Lett. 33:L18301 
Kuvshinov AV, Sabaka TJ, Olsen N. 2006. 3-D electromagnetic induction studies using the Swarm constellation: mapping conductivity anomalies in the Earth's mantle. Earth Planets Space 58:417-27

Kuvshinov AV, Utada H, Avdeev D, Koyama T. 2005. 3-D modelling and analysis of Dst C-responses in the North Pacific Ocean region, revisited. Geophys. 7. Int. 60:505-26

Langel RA. 1987. The main field. In Geomagnetism, ed. JA Jacobs, 1:249-512. London: Academic

Langel RA, Estes RH. 1985a. Large-scale, near-Earth magnetic fields from external sources and the corresponding induced internal field. 7. Geophys. Res. 90:2487-94

Langel RA, Estes RH. 1985b. The near-Earth magnetic field at 1980 determined from Magsat data. F. Geophys. Res. 90:2495-509

Langel RA, Hinze WJ. 1998. The Magnetic Field of the Earth's Lithosphere: The Satellite Perspective. Cambridge, UK: Cambridge Univ. Press

Langel RA, Mead GD, Lancaster ER, Estes RH, Fabiano EB. 1980. Initial geomagnetic field model from Magsat vector data. Geophys. Res. Lett. 7:793-96

Langel RA, Purucker M, Rajaram M. 1993. The equatorial electrojet and associated currents as seen in Magsat data. F. Atmos. Terr. Phys. 55:1233-69

Langel RA, Ridgway JR, Sugiura M, Maezawa K. 1988. The geomagnetic field at 1982 from DE-2 and other magnetic field data. 7. Geomagn. Geoelectr. 40:1103-27

Langlais B, Mandea M, Ultré-Guérard P. 2003. High-resolution magnetic field modeling: application to MAGSAT and Ørsted data. Phys. Earth Planet. Inter. 135:77-91

Lesur V, Olsen N, Thomson AW. 2011. Geomagnetic core field models in the satellite era. In Geomagnetic Observations and Models, ed. M Mandea, M Korte, IAGA Spec. Sopron Book Ser. 5:277-94. Dordrecht: Springer

Lesur V, Wardinski I, Hamoudi M, Rother M. 2010. The second generation of the GFZ Reference Internal Magnetic Model: GRIMM-2. Earth Planets Space 62:765-73

Lühr H, Liu H, Park J, Müller S. 2011. New aspects of the coupling between thermosphere and ionosphere, with special regards to CHAMP mission results. In Aeronomy of the Earth's Atmosphere and Ionosphere, ed. MA Abdu, D Pancheva, IAGA Spec. Sopron Book Ser. 2:303-16. Dordrecht: Springer

Lühr H, Maus S. 2006. Direct observation of the $F$ region dynamo currents and the spatial structure of the EEJ by CHAMP. Geophys. Res. Lett. 33:L24102

Lühr H, Maus S. 2010. Solar cycle dependence of quiet-time magnetospheric currents and a model of their near-Earth magnetic fields. Earth Planets Space 62:843-48

Lühr H, Maus S, Rother M. 2004. Noon-time equatorial electrojet: its spatial features as determined by the CHAMP satellite. 7. Geophys. Res. 109:A01306

Lühr H, Maus S, Rother M, Cooke D. 2002. First in-situ observation of night-time F region currents with the CHAMP satellite. Geophys. Res. Lett. 29:1489

Lühr H, Rother M, Häusler K, Alken P, Maus S. 2008. The influence of nonmigrating tides on the longitudinal variation of the equatorial electrojet. 7. Geophys. Res. 113:A08313

Lühr H, Rother M, Maus S, Mai W, Cooke D. 2003. The diamagnetic effect of the equatorial Appleton anomaly: its characteristics and impact on geomagnetic field modeling. Geophys. Res. Lett. 30:1906

Maeda H, Iyemori T, Araki T, Kamei T. 1982. New evidence of a meridional current system in the equatorial ionosphere. Geophys. Res. Lett. 9:337-40

Mandea M, Holme R, Pais A, Pinheiro K, Jackson A, Verbanac G. 2010. Geomagnetic jerks: rapid core field variations and core dynamics. Space Sci. Rev. 155:147-75

Manoj C, Lühr H, Maus S, Nagarajan N. 2006. Evidence for short spatial correlation lengths of the noontime equatorial electrojet inferred from a comparison of satellite and ground magnetic data. 7. Geophys. Res. 111:A11312

Maus S. 2007. CHAMP magnetic mission. See Gubbins \& Herrero-Bervera 2007, pp. 59-60

Maus S. 2010a. Magnetic field model MF7. http://www.geomag.us/models/MF7.html

Maus S. 2010b. NGDC-720 lithospheric magnetic model. http://www.geomag.us/models/ngdc720.html

Maus S, Lühr H. 2005. Signature of the quiet-time magnetospheric magnetic field and its electromagnetic induction in the rotating Earth. Geophys. F. Int. 162:755-63

Maus S, Lühr H. 2006. A gravity-driven electric current in the Earth's ionosphere identified in CHAMP satellite magnetic measurements. Geophys. Res. Lett. 33:L02812 
Maus S, Lühr H, Balasis G, Rother M, Mandea M. 2005a. Introducing POMME, the POtsdam Magnetic Model of the Earth. In Earth Observation with CHAMP: Results from Three Years in Orbit, ed. C Reigber, H Lühr, P Schwintzer, J Wickert, pp. 293-98. Berlin: Springer-Verlag

Maus S, Lühr H, Rother M, Hemant K, Balasis G, et al. 2007. Fifth-generation lithospheric magnetic field model from CHAMP satellite measurements. Geochem. Geophys. Geosyst. 8:Q05013

Maus S, McLean S, Dater D, Lühr H, Rother M, et al. 2005b. NGDC/GFZ candidate models for the 10th generation International Geomagnetic Reference Field. Earth Planets Space 57:1151-56

Maus S, Rother M, Stolle C, Mai W, Choi S, et al. 2006. Third generation of the Potsdam Magnetic Model of the Earth (POMME). Geochem. Geophys. Geosyst. 7:Q07008

Maus S, Weidelt P. 2004. Separating the magnetospheric disturbance magnetic field into external and transient internal contributions using a 1D conductivity model of the Earth. Geophys. Res. Lett. 31:L12614

Oberheide J, Forbes J, Häusler K, Wu Q, Bruinsma S. 2009. Tropospheric tides from 80 to 400 km: propagation, interannual variability, and solar cycle effects. 7. Geophys. Res. 114:D00I05

Olsen N. 1996. A new tool for determining ionospheric currents from magnetic satellite data. Geophys. Res. Lett. 23:3635-38

Olsen N. 1997. Ionospheric $F$ region currents at middle and low latitudes estimated from Magsat data. 7. Geophys. Res. 102:4563-76

Olsen N. 1999a. Induction studies with satellite data. Surv. Geophys. 20:309-40

Olsen N. 1999b. Long-period (30 days-1 year) electromagnetic sounding and the electrical conductivity of the lower mantle beneath Europe. Geophys. 7. Int. 138:179-87

Olsen N. 2002. A model of the geomagnetic field and its secular variation for epoch 2000 estimated from Ørsted data. Geophys. 7. Int. 149:454-62

Olsen N. 2007. Ørsted. See Gubbins \& Herrero-Bervera 2007, pp. 743-45

Olsen N, Haagmans R, Sabaka TJ, Kuvshinov AV, Maus S, et al. 2006a. The Swarm End-To-End mission simulator study: separation of the various contributions to Earth's magnetic field using synthetic data. Earth Planets Space 58:359-70

Olsen N, Holme R, Hulot G, Sabaka T, Neubert T, et al. 2000. Ørsted Initial Field Model. Geophys. Res. Lett. $27: 3607-10$

Olsen N, Hulot G, Sabaka TJ. 2010. Sources of the geomagnetic field and the modern data that enable their investigation. In Handbook of Geomathematics, ed. W Freeden, Z Nashed, T Sonar, pp. 106-24. Heidelberg: Springer

Olsen N, Lühr H, Sabaka TJ, Mandea M, Rother M, et al. 2006b. CHAOS—a model of Earth's magnetic field derived from CHAMP, Ørsted, and SAC-C magnetic satellite data. Geophys. 7. Int. 166:67-75

Olsen N, Lühr H, Sabaka TJ, Michaelis I, Rauberg J, Tøffner-Clausen L. 2011. The CHAOS-4 Geomagnetic Field Model. http://www.space.dtu.dk/English/Research/Scientific_data_and_models/Magnetic_ Field_Models.aspx

Olsen N, Mandea M. 2008. Rapidly changing flows in the Earth's core. Nat. Geosci. 1:390-94

Olsen N, Sabaka TJ, Lowes F. 2005. New parameterization of external and induced fields in geomagnetic field modeling, and a candidate model for IGRF 2005. Earth Planets Space 57:1141-49

Pais MA, Jault D. 2008. Quasi-geostrophic flows responsible for the secular variation of the Earth's magnetic field. Geophys. 7. Int. 173:421-43

ParkJ, Lühr H, Min KW. 2010. Characteristics of $F$-region dynamo currents deduced from CHAMP magnetic field observations. 7. Geophys. Res. 115:A10302

Park J, Lühr H, Min KW. 2011. Climatology of the inter-hemispheric field-aligned current system in the equatorial ionosphere as observed by CHAMP. Ann. Geophys. 29:573-82

Park J, Lühr H, Stolle C, Rother M, Min KW, Michaelis I. 2009. The characteristics of field-aligned currents associated with equatorial plasma bubbles as observed by the CHAMP satellite. Ann. Geophys. 27:2685-97

Pedatella NM, Forbes JM, Richmond AD. 2011. Seasonal and longitudinal variations of the solar quiet $(S q)$ current system during solar minimum determined by CHAMP satellite magnetic field observations. 7. Geophys. Res. 116:A04317

Purucker ME. 2007. Magsat. See Gubbins \& Herrero-Bervera 2007, pp. 673-74

Regan RD, Cain JC, Davis WM. 1975. A global magnetic anomaly map. F. Geophys. Res. 80:794-802 
Richmond AD. 1995. Ionospheric electrodynamics using Magnetic Apex Coordinates. F. Geomagn. Geoelectr. 47:191-212

Richmond AD. 2002. Modeling the geomagnetic perturbations produced by ionospheric currents, above and below the ionosphere. 7. Geodyn. 33:143-56

Rishbeth H. 1997. The ionospheric E-layer and F-layer dynamos-a tutorial review. 7. Atmos. Solar-Terr. Phys. 59:1873-80

Ritter P, Lühr H. 2006. Curl-B technique applied to Swarm constellation for determining field-aligned currents. Earth Planets Space 58:463-76

Ritter P, Lühr H, Maus S, Viljanen A. 2004. High-latitude ionospheric currents during very quiet times: their characteristics and predictability. Ann. Geophys. 22:2001-14

Sabaka TJ, Olsen N, Langel RA. 2002. A comprehensive model of the quiet-time near-Earth magnetic field: Phase 3. Geophys. F. Int. 151:32-68

Sabaka TJ, Olsen N, Purucker ME. 2004. Extending comprehensive models of the Earth's magnetic field with Ørsted and CHAMP data. Geophys. 7. Int. 159:521-47

Stolle C, Lühr H, Rother M, Balasis G. 2006. Magnetic signatures of equatorial spread F, as observed by the CHAMP satellite. 7. Geophys. Res. 111:A02304

Sugiura M. 1964. Hourly values of equatorial Dst for the IGY. Ann. Int. Geophys. Year 35:9-45

Takeda M. 1996. Effects of the strength of the geomagnetic main field strength on the dynamo action in the ionosphere. 7. Geophys. Res. 101:7875-80

Thébault E, Purucker M, Whaler KA, Langlais B, Sabaka TJ. 2010. The magnetic field of the Earth's lithosphere. Space Sci. Rev. 155:95-127

Thébault E, Vervelidou F, Lesur V, Hamoudi M. 2012. The satellite along-track analysis in planetary magnetism. Geophys. F. Int. 188:891-907

Thomson AWP, Lesur V. 2007. An improved geomagnetic data selection algorithm for global geomagnetic field modelling. Geophys. 7. Int. 169:951-63

Tøffner-Clausen L, Sabaka TJ, Olsen N. 2010. End-to-End Mission Simulation study (E2E+). Presented at Second Int. Swarm Sci. Meet, June 24-26, 2009, Noordwijk, Neth. http://www.congrex.nl/09c24/ S2_Posters/S2_P14_Toffner_paper.pdf

Tyurmina LO, Cherevko TN. 1967. Some results of a spherical harmonic analysis of the geomagnetic field from COSMOS 49 data. Geomagn. Aeron. (Engl. Transl.) 7:917

van Sabben D. 1966. Magnetospheric currents, associated with the N-S asymmetry of Sq. F. Atmos. Terr. Phys. 28:965-81

van Sabben D. 1970. Solstitial Sq-currents through the magnetosphere. F. Atmos. Terr. Phys. 32:1331-36

Velímsky J. 2010. Electrical conductivity in the lower mantle: constraints from CHAMP satellite data by time-domain EM induction modelling. Phys. Earth Planet. Inter. 180:111-17

Velímsky J, Martinec Z, Everett ME. 2006. Electrical conductivity in the Earth's mantle inferred from CHAMP satellite measurements: 1. Data processing and 1-D inversion. Geophys. 7. Int. 166:529-42

Xiong C, Park J, Lühr H, Stolle C, Ma SY. 2010. Comparing plasma bubble occurrence rates at CHAMP and GRACE altitudes during high and low solar activity. Ann. Geophys. 28:1647-58

Yamashita S, Iyemori T. 2002. Seasonal and local time dependence of the interhemispheric field-aligned currents deduced from the Orsted satellite and the ground magnetic observations. Ann. Geophys. 25:701-9 
Annual Review of Earth and Planetary Sciences

Volume 40, 2012

\section{Contents}

Reminiscences From a Career in Geomicrobiology

Henry L. Ebrlich

Mixing and Transport of Isotopic Heterogeneity

in the Early Solar System

Alan P. Boss

Tracing Crustal Fluids: Applications of Natural ${ }^{129} \mathrm{I}$ and ${ }^{36} \mathrm{Cl}$

Udo Febn

SETI@home, BOINC, and Volunteer Distributed Computing

Eric 7. Korpela

End-Permian Mass Extinction in the Oceans: An Ancient Analog for the Twenty-First Century?

Jonathan L. Payne and Matthew E. Clapham

Magma Oceans in the Inner Solar System

Linda T. Elkins-Tanton

History of Seawater Carbonate Chemistry, Atmospheric $\mathrm{CO}_{2}$, and Ocean Acidification Richard E. Zeebe

Biomimetic Properties of Minerals and the Search for Life in the Martian Meteorite ALH84001

Jan Martel, David Young, Hsin-Hsin Peng, Cheng-Yeu Wu, and Fobn D. Young .... 167

Archean Subduction: Fact or Fiction?

feroen van Hunen and Jean-François Moyen

Molecular Paleohydrology: Interpreting the Hydrogen-Isotopic

Composition of Lipid Biomarkers from

Photosynthesizing Organisms

Dirk Sachse, Isabelle Billault, Gabriel 7. Bowen, Yoshito Chikaraishi, Todd E. Dawson, Sarab 7. Feakins, Katherine H. Freeman, Clayton R. Magill, Francesca A. McInerney, Marcel T.F. van der Meer, Pratigya Polissar, Richard 7. Robins, Zulian P. Sachs, Hanns-Ludwig Schmidt, Alex L. Sessions, James W.C. White, Jason B. West, and Ansgar Kabmen 
Building Terrestrial Planets

A. Morbidelli, 7.I. Lunine, D.P. O'Brien, S.N. Raymond, and K.F. Walsh

Paleontology of Earth's Mantle

Norman H. Sleep, Dennis K. Bird, and Emily Pope

Molecular and Fossil Evidence on the Origin of Angiosperms

James A. Doyle

Infrasound: Connecting the Solid Earth, Oceans, and Atmosphere

M.A.H. Hedlin, K. Walker, D.P. Drob, and C.D. de Groot-Hedlin

Titan's Methane Weather

Henry G. Roe

Extratropical Cooling, Interhemispheric Thermal Gradients, and Tropical Climate Change

John C.H. Chiang and Andrew R. Friedman

The Role of $\mathrm{H}_{2} \mathrm{O}$ in Subduction Zone Magmatism

Timothy L. Grove, Christy B. Till, and Michael F. Krawczynski

Satellite Geomagnetism

Nils Olsen and Claudia Stolle

The Compositions of Kuiper Belt Objects

Michael E. Brown 467

Tectonics of the New Guinea Region

Suzanne L. Baldwin, Paul G. Fitzgerald, and Laura E. Webb

Processes on the Young Earth and the Habitats of Early Life

Nicholas T. Arndt and Euan G. Nisbet

The Deep, Dark Energy Biosphere: Intraterrestrial Life on Earth

Katrina 7. Edwards, Keir Becker, and Frederick Colwell

Geophysics of Chemical Heterogeneity in the Mantle

Lars Stixrude and Carolina Lithgow-Bertelloni

The Habitability of Our Earth and Other Earths: Astrophysical,

Geochemical, Geophysical, and Biological Limits on Planet

Habitability

Charles H. Lineweaver and Aditya Chopra

The Future of Arctic Sea Ice

Wieslaw Maslowski, Jaclyn Clement Kinney, Matthew Higgins, and Andrew Roberts

The Mississippi Delta Region: Past, Present, and Future

Michael D. Blum and Harry H. Roberts 
Climate Change Impacts on the Organic Carbon Cycle at the Land-Ocean Interface

Elizabeth A. Canuel, Sarab S. Cammer, Hadley A. McIntosh, and Christina R. Pondell

\section{Indexes}

Cumulative Index of Contributing Authors, Volumes $31-40 \ldots \ldots \ldots \ldots \ldots \ldots \ldots 713$

Cumulative Index of Chapter Titles, Volumes 31-40 ......................... 717

\section{Errata}

An online log of corrections to Annual Review of Earth and Planetary Sciences articles may be found at http://earth.annualreviews.org 